\title{
The Influence of Employee Engagement, Work Environment and Job Satisfaction on Organizational Commitment and Performance of Employees: A Sampling Weights in PLS path Modelling
}

\author{
Isaac Ahakwa $1^{*}$, Jingzhao Yang ${ }^{2}$, Evelyn Agba Tackie ${ }^{\circledR 3}$, Samuel Atingabili $₫ 4$ \\ 1,2,3,4 School of Management, Jiangsu University, Zhenjiang-China \\ * Corresponding author: isaacahakwa@gmail.com
}

\begin{abstract}
Article History
Received 2021-04-15

Revised 2021-05-02

Accepted 2021-05-03

Published 2021-05-04
\end{abstract}

\section{Keywords}

Employee performance

Organizational commitment

Work environment

Weighted partial least squares

Ghana.

How to cite?

Ahakwa, I., Yang, J., Tackie, E. A., \&

Atingabili, S. (2021). The Influence of

Employee Engagement, Work

Environment and Job Satisfaction on

Organizational Commitment and

Performance of Employees: A Sampling

Weights in PLS path Modelling.

SEISENSE Journal of Management,

4(3), 34-62. doi:

10.33215/sjom. $24 i 3.641$

Copyright (C) 2021 The Author(s)

(cc) BY
Purpose- This paper explored the link between employee engagement, work environment, and job satisfaction on organizational commitment and employee performance in Ghana's Banking sector considering moderated-mediated interaction.

Design/Methodology- Data were obtained from seven hundred and twenty (720) employees from selected financial banks in the Greater Accra Region of Ghana through simple random probability sampling. However, seven hundred (700) responses were deemed accurate and therefore used in the analysis. In the analytical process, Weighted Partial Least Squares (WPLS) and Partial Least Squares (PLS) based on Structural Equation Modeling (SEM) were employed.

Findings- From the findings, the studied data for both WPLS-SEM and PLS-SEM models met internal consistency reliability, convergent, and discriminant validity. Also, organizational commitment fully mediated the link between work environment and employee performance in the WPLS-SEM model compared to PLS-SEM with partial mediation. It was statistically significant at $\mathrm{p}<0.01$.

Practical Implications- Based on the findings, it's recommended that organizations and managers focus on developing the workers' workplace environment in numerous ways. This should entail valuing workers' contributions, communicating the company's progress and achievement to workers, thus instilling ownership in workers, providing them with a work-life balance, providing the requisite knowledge and tools for successful production, and providing a stable atmosphere. The workplace of all these factors could increase workers' morale and lead to increased productivity. 


\section{Introduction}

In light of challenging economic circumstances, any establishment's sustainable growth relies on workers' increased performance. Employee performance (EP) is the successful and reliable execution of the duty in a demanding environment using the stipulated period's tools. EP is linked to the activities carried out to achieve organizations' goals and objectives (Motowidlo, Lievens, \& Ghosh, 2018). The organization's creation is primarily focused on the EP as it affects efficiency (Chikazhe, Makanyeza, \& Kakava, 2020), and lack of required productivity affects the organization's sustainability (Anyakoha, 2019). EP is critical because it generates optimal organizational efficiency (Abdirahman, 2018). Increased level of dedication serves as the driving force behind EP. When evaluating the impact of organizational commitment (OC), several studies reinforce the belief that OC inspires workers to perform to the highest efficiency standards (Berberoglu, 2015).

The importance of the results of the study cannot be devalued. First, this study's findings would allow companies to build practical human capital management approaches to improve their corporations' overall value. Next, the results of this study will encourage decision-makers to create tailored strategies and initiatives that will positively inspire the development and survival of organizations around the world. Third, the research's results could be used by controlling bodies such as the Bank of Ghana and other financial bodies to advance their regulatory structure further. Finally, the research provides more modernized scientific data to current human resource management literature in Ghana concerning OC and EP. This is of immense value to the academic field, as it serves as reference material for students and scholars who may wish to do further exploration on the current topic.

Several antecedents of employee performance have been examined and investigated by prior studies. For example, leadership practices (Le \& Tran, 2020); motivation (Ackah, 2014); training and development (Ampomah, 2016; Boadu, Dwomo-Fokuo, Boakye, \& Kwaning, 2014); leaders' behavior (Obuobisa-Darko, 2019) and communication (Otoo, 2016). However, very little has been done on variables such as employee engagement (EE), work environment (WE), and OC in the Ghanaian context. This research was conducted to aid fill this gap. Studies on EP, OC, job satisfaction (JS), EE, and WE are abundant. The conclusions are, however, inconsistent. For, e.g., (Cesário \& Chambel, 2017) researched EP, OC, and EE in Portugal. As a result, there was a positive correlation between EP and OC and between EE and EP. Eliyana and Ma'arif (2019) have discussed the relationships between EP, JS, and OC in Indonesia. It was reported that there was a strong association between JS and EP. There was, however, a negative correlation between OC and EP. Abdirahman (2018) examined the influence of JS and OC on EP in Malaysia. The findings indicated a positive relationship between JS and EP and amid OC and EP. In the public sector of Ghana, Amoako-Asiedu and Obuobisa-Darko (2017) examined the interrelationship between EE and EP. A significant linkage between EE and EP was obtained from the findings. Ahakwa, Yang, Agba Tackie, Afotey Odai, and Dartey (2021) delved into the relationship between WE and OC among MMDAs employees in Ghana. From the finding, there was a significant positive connection between the two variables. The studies as mentioned above, among others, are deficient in scope as most human resource management studies related to OC and EP in Ghana are more associated with organizations operating in the primary and industrial sectors, to the detriment of those operating in the service field, to the best of our knowledge. By focusing on only accredited banking organizations in Ghana, this study contributively fills that gap. The research adds in the following ways to the current body of literature:

First, most previous studies studied the relations between OC, EE, WE, JS, and EP using partial least squares focused on structural equation modeling (SEM). Most studies, however, neglect the Weighted PLS-SEM (WPLS-SEM). WPLS-SEM uses weighed correlations and weighted regression results to estimate the PLS path model (Becker \& Ismail, 2016). The WPLS-SEM permits investigators to specify a weighting vector that 
determines the importance of each observation's results. This study employed WPLS-SEM and compared the result with the original PLS-SEM. This study also used the current method of assessing the model's predictive relevance, "the PLSpredict" proposed by (Hair et al., 2020; Shmueli et al., 2019), which is not common in existing studies.

Second, numerous studies of OC, EE, WE, JS, and EP have been done. However, only a small number of those studies considered the issue of common method bias (CMB). According to Kock (2015), a probable cause of CMB is the implicit social desirability allied with answering questions in a questionnaire in a particular way, again causing the indicators to share a certain amount of common variation. To help address CMB's issue, the researchers provided appropriate reliability evidence, factor structures, and convergent and discriminant validity as suggested by (Conway \& Lance, 2010). A full collinearity assessment approach proposed by Kock (2015) was also employed to deal with CMB's issue.

Third, numerous studies of OC, EE, WE, JS, and EP have been done. However, only a small number of those studies considered either mediation or moderation in their analysis model. To the best of our knowledge, this is the first study to report on this study's variables in moderated-mediated interaction in the Ghanaian context upon an extant review of the literature. Therefore, this research aims to fill the gap by creating an integrative model that considers many variables and mechanisms relevant to EP, a moderated-mediated model.

Last, most existing studies end up using a small sample size for their analysis when using PLS-SEM. According to Fornell and Bookstein (1982), when models contain several constructions and a wide number of objects, PLS-SEM proposes better solutions with small sample sizes. Hair Jr, Hult, Ringle, and Sarstedt (2016) suggest that "some researchers have wrongly and misleadingly used these features to produce studies with exceedingly small sample sizes, even when the population is large and accessible without much effort." Unlike other studies, this research used a larger sample size of seven hundred (700) for the study's analysis. Such a larger sample size provides more accurate mean values and gives a smaller margin of error. Wamba et al. (2017) indicated that "a greater number of prior studies on sample size requirements in PLS-SEM unnoticed the fact that the process also proves valuable for evaluating large data quantities."

The contributions mentioned above are novel since they are deficient in OC and EP studies undertaken in the Ghanaian context. The study is eventually unique since the investigators themselves carried it out; the study's hypothesis and intent are clearly defined; the techniques used are fully detailed; the findings are properly represented, and the policy implications are properly explained. The rest of the report is organized as follows: the "Review of Related Literature" section presents the literature promoting the subject under study. At the same time, the "Method" part reflects the study technique. Empirical findings of the analysis are summarized in the "Empirical Results" section, while discussions, practical implications, and conclusions are the final section of the research.

\section{Review of Related Literature}

\section{Employee Engagement}

EE is an important term in an organization, which has gained substantial interest in scholarly study. Saks (2019) referred to the EE as the degree that one is conscientious and involved in his/her work roles. Also, "EE is perceived as a good and satisfactory behavior associated with work that is marked by three components: vigor, interest and devotion" (Rothmann, 2017). "An engaged employee is projected to experience traits such as socially, psychologically and cognitively" (W. Kim, Khan, Wood, \& Mahmood, 2016). Kang and Sung (2017) described EE as "the degree of participation, communication, intimacy and impact of an employee with a specific brand, the involvement of an employee with a brand, irrespective of the medium where they make the 
decisions." Furthermore, (Hanaysha, 2016a) conceived of EE as the productive, interpersonal, emotional conduct of work, motivating workers to mentally, cognitively, and physically express and plan for their duties.

To obtain valuable market success results for various organizations, the EE, according to Rothmann (2017), is extremely significant. The authors have shown that it is important for companies to involve their workers, as EE establishments have a greater degree of customer satisfaction and commitment, extra efficient, and profitable than those with less EE (Rothmann, 2017). Hanaysha (2016a) has recommended cultivating EE's idea as retrenchment reduces workers' motivation and devotion to their establishments. Therefore, low amounts of dedication have a detrimental impact on the OC and retaining of workers. Jiony, Tanakinjal, Gom, and Siganul (2015) suggested that a well-performing company is dependent on its ability to maintain a safe, engaged and dedicated workforce through interaction.

\section{Organizational Commitment}

It is undoubtedly very required for all establishments to cultivate OC since personnel is the key foundation of sustained achievement and efficiency. "OC is described as an emotional attitude that binds personnel to an establishment in a way that decreases turnover intention" (Ahakwa, Yang, Agba Tackie, et al., 2021). Lee, Ashford, Walsh, and Mowday (1992) proposed the most generally accepted definition for OC as "the level to which a person's participation in his organization." The authors added that loyalty is demonstrated by an employee's ability to labor successfully in an establishment and the desire to sustain the relationship devoid of attempting to turn to another (Lee et al., 1992). Organizations with greatly committed personnel, since it's widely agreed that OC might lead to countless organizational results; reduced turnover, greater motivation level, enriched citizenship conduct, and continuous organizational support (Ahakwa, Yang, Agba Tackie, et al., 2021). "The commitment of workers is a sign of greater devotion and improved efficiency" (Porter, Steers, Mowday, \& Boulian, 1974). Committed personnel often work assiduously to fulfill objectives of establishment and appear to positively consent to their values (C. S. Cheah, Chong, Yeo, \& Pee, 2016). Many positive behavioral outcomes can be correlated with OC of employees, such as greater retention of workers, motivation, efficiency, quality of work, and willingness to make sacrifices to enhance the reputation and performance of organizations (Somers, 1995). OC is a crucial element in assessing organizations' effectiveness, which increases employee morale and EE (Hayat, Azeem, Nawaz, Humayon, \& Ahmed, 2019; Hendri, 2019; Yousef, 2017). OC often has a clear correlation with the actions and performance of employees. If an employee has an OC, there will be fewer chances for absence and turnover (R. Ahmad, Islam, \& Saleem, 2019; Igbaria \& Greenhaus, 1992; Joe-Akunne \& Ezeh, 2019; Karunarathne \& Wickramasekara, 2020). Therefore, it is crucial to regularly review employees' commitment to resolving any problems that may occur and ensure that workers maintain a good attitude to work, which is indispensable to overall organizational success.

\section{Work Environment}

The WE is a significant element that influences the JS and OC of employees to the organization. The WE refers to the surrounding of an establishment where employees do their work. "The WE is linked to the atmosphere of a specific company in which its workers conduct their duties" (Danish, Ramzan, \& Ahmad, 2013). Undoubtedly, since their needs are likely to be fulfilled, a facilitative and healthy work atmosphere will attract employees. To succeed, companies should design their WE to enhance employees' dedication and motivation that eventually contribute to promising results. A good WE include all the essentials of a job, such as the amenities to perform responsibilities, a relaxed workspace, protection, and no noise. Hanaysha (2016a) found that, relative to those who feel insecure, workers who feel relaxed with their WE are likely to work more efficiently and enjoy the working process. Managers should also strengthen the elements of the WE to make certain of the well-being of their workforces. Past research demonstrates that WE can be measured in many respects. Ahakwa, Yang, Agba Tackie, et al. (2021) indicated that "the WE involves elements such as participation; group cohesion; provision for supervisors; role direction; self-sufficiency; clarity; creativity, 
physical well-being, and management power." Also, Ahakwa, Yang, Agba Tackie, et al. (2021) defined a range of dimensions for assessing the WE, including: "job challenge, job autonomy, leader concern, and support, leader work facilitation, working group cooperation, workgroup spirit, position uncertainty, fairness and reward system equity. Therefore, the WE may be evaluated in terms of any factor that influences the actions of an employee in his or her organization.

\section{Employee Job Satisfaction}

JS is the wonderful psychological state arising from the enjoyment of a person's own work experience (Liu, Aungsuroch, \& Yunibhand, 2016). It could also be perceived as workers' mindset towards their employers, the environment of corporate, social, and physical work, and the benefits received (Yousef, 2017). JS implies how a member of the organization feels about work (Qureshi \& Hamid, 2017). Such emotions may be positive or negative; more positive feelings indicate JS's degree is high. JS also defines a worker's optimistic feelings about the workplace. Judge and Locke (1993) showed a strong correlation between the features of the work and people's desires. There is also a consensus among scholars that Maslow's theory of needs clarifies this association between work characteristics and human needs. Stajkovic and Luthans (1998) suggested that JS has three components; first, JS refers to an employee's emotional reaction to WE. Second, JS may be calculated by estimating how well results fulfill requirements. Last, JS can be assessed by many behaviors relevant to work. The success management framework often stresses JS employees (N. Ahmad, Iqbal, Javed, \& Hamad, 2014). JS is to build optimistic feelings among employees regarding jobs Robbin and Judge's (2008). Greater JS produces more optimistic thoughts about their jobs in the minds of workers. Badran and Youssef-Morgan (2015) found out that JS induces optimistic emotional feelings arising from job appraisal.

\section{Employee Performance}

Performance is defined as the product of trained employees in some particular circumstances (Obicci, 2015). EP is the product or degree of an employee as a whole's progress in executing the task over a given amount of time relative to other things, such as the quality of work, objective, or standards that have been previously defined and collectively decided upon (Obicci, 2015). Vrinda and Jacob (2015) observed a dispute between the personal life and performance of workers. Dahie, Takow, Nur, and Osman (2016) examined that performance effectively is the product of work with a fair corporate responsibility without interrupting any regulations and organizational objectives. Darma and Supriyanto (2017) say that EP results from perfection and everyone's quantity in directing his/her job obligations.

\section{Hypotheses Development and Conceptual Framework}

\section{Employee Engagement and Organizational Commitment}

Previous findings have uncovered that EE has a significant positive influence on OC (Hanaysha, 2016a; Imam \& Shafique, 2014; Nazir \& Islam, 2017). Engaged workers make greater attempts to work assiduously, are highly likely to drive further than their necessary and anticipated number of work assignments (Lockwood, 2007). Also, engaged workers tend to find their working conditions and workplace principles positively impact their physical and psychological security at work (Agyemang \& Ofei, 2013). Schaufeli (2013) previous research has indicated that EE influences the degree of OC.

H1: Employee engagement positively influences organizational commitment.

\section{Employee Engagement and Employee performance}

Past studies have made known that EE has a significant positive influence on EP (Anitha, 2014; Ayub \& Islam, 2018; Sendawula, Kimuli, Bananuka, \& Muganga, 2018). However, Kuruppuge and Gregar (2017) identified a negative relationship between EE and EP. The level of loyalty strongly influences the degree of EP that an 
individual has to his company and its beliefs (Sendawula et al., 2018). A dedicated worker is mindful of the corporate setting and partners with peers to enhance job efficiency for the organization's benefit (Anindita \& Seda, 2018). EE is regarded as capacity, interest, participation, effectiveness, vigor, motivation, excitement, and a positive state (Men, O’Neil, \& Ewing, 2020). Truss, Shantz, Soane, Alfes, and Delbridge (2013), revealed that "committed workers have a healthy mindset and a work-based state of mind marked by vigor, commitment, and interest, making staff mentally present at work, reducing their tendency to make mistakes and errors related to work." Employees who are engaged are more prepared to know new things, according to (Sugianingrat et al., 2019). This demonstrates that engaged employees are able to put their ideas into motion and, as a result, reach high levels of success at work (Sugianingrat et al., 2019). Kruse (2012) examined 28 research studies by various scholars and discovered a connection between EE and operation, revenue, pricing, safety, productivity, earnings, and overall profitability. Monica and Krishnaveni (2018), who expressed that engaged workers frequently portray a strong positive emotional bond with their job and are frequently more active, efficient, stronger, happier, and less likely to abandon their employer, all support the correlation between EE and EP. This result is also in line with Dhir and Shukla (2018), who performed a meta-analysis and discovered that EE is linked to higher performance, consumer retention, and therefore customer loyalty. Employees who are engaged outperform their discontented colleagues (Shuck, Reio Jr, \& Rocco, 2011).

H2: Employee engagement positively influences employee performance.

\section{Work Environment and Organizational Commitment}

A variety of studies have found that the WE has had a major positive impact on OC (Ahakwa, Yang, Tackie, Odai, \& Dartey, 2021; Hanaysha, 2016a; Khuong \& Le Vu, 2014). Pitaloka and Sofia (2014) establish a positive impact on JS and OC in a conducive WE. Haggins (2011) established that WE played an important role in persuading OC. By Giffords (2009), one of the key contributors to OC is the WE. According to Rayton (2006), a safe working atmosphere, clear connectivity, and an adequate workload are deciding factors in an employee's OC. If this aspect is lacking, people no longer feel at ease; they only come to work and work when their thoughts are elsewhere; they have no compelling excuse to remain and survive in the organization. Employees who work in a pleasant environment feel more committed, according to (Zainudin, Rashid, Murugeesan, Che Zainal, \& Malek, 2019). Also, a comfortable WE will lead to increased employee commitment (Nwachukwu, Ezeh, Ogochukwu, Nkechinyere, \& Dumle, 2019). Among bankers, Karacsony (2019) discovered a negative connection between employee environment stressors and organizational engagement. According to Hanaysha (2016a), the WE has a significant impact on OC. According to Hanaysha (2016a), the workplace atmosphere tailored to the workforce demonstrates commitment on the part of the company.

H3: Work environment positively influences organizational commitment.

\section{Work Environment and employee performance}

Past studies have shown that WE have a significant positive effect on EP (Badrianto \& Ekhsan, 2020; Imran, Fatima, Zaheer, Yousaf, \& Batool, 2012; Nguyen, Dang, \& Nguyen, 2015; Rorong, 2016). According to E. M. Putri, Ekowati, Supriyanto, and Mukaffi (2019), WE are among the variables that impact EP. The study conducted by E. M. Putri et al. (2019) indicated that the agency's WE could positively and significantly affect EP. According to Rorong (2016), the office atmosphere's practical décor and design eventually helped enhance workers' experiences and necessitate improved efficiency. Previous researchers stated that the physical working environment helped to deter employees' ability to connect with their work roles and influence their behavior (Al-Omari \& Okasheh, 2017). A study had shown that a conducive physical working environment could reduce absenteeism and enhance employee performance (Chandrasekar, 2011). Thus, to retain employee performance, the organization had to improve the physical working environment. Nematchoua, Ricciardi, Orosa, Asadi, and 
Choudhary (2019), revealed that a suitable workplace temperature energizes an office occupier to work at the employee's best.

H4: Work environment positively influences employee performance.

\section{Organizational commitment and employee performance}

The OC and EP relationship is confirmed by historical research. Hidayah and Tobing (2018) clarify that OC affects EP. The findings suggest that OC types, such as continuous, normative, and affective, are related to employee job efficiency. Susanty and Miradipta (2013) reveal the effect of OC on EP. The results showed that OC forecasts EP separately and jointly. The studies carried out on university teachers have concluded that OC has a favorable association with EP. The OC and EP are being studied by Suliman and Iles (2000) in three industrial units. This research has demonstrated that organizational participation is a three-dimensional phenomenon and has a beneficial association with job efficiency.

Another research indicates that OC has a favorable association with work efficiency. Dixit and Bhati (2012) observed that employee motivation is an essential concern because it can forecast EP, absenteeism, and other activities. Employees with a high level of organizational responsibility are more efficient and profitable, which benefits the organization as a whole (Paramita, Lumbanraja, \& Absah, 2020). OC has a significant and constructive association with performance. According to Ramli (2019) organizational commitment is an antecedent that can function to determine job performance. According to (Paramita et al., 2020), OC is linked to EP. According to Singh (2019), OC has a favorable relationship with overall job results. Barrick, Stewart, and Piotrowski (2002) discussed and identified a constructive association and a precise effect between OC and EP. Fu and Deshpande (2014) discovered that OC has an important and beneficial impact on EP. Similarly, Jamal (2011) demonstrates that OC has a direct impact on employee success.

H5: Organizational commitment positively influence employee performance.

\section{The link between Job Satisfaction and employee performance}

Chaudhry, Jariko, Mushtaque, Mahesar, and Ghani (2017) suggested that satisfaction and EP are correlated to one another, and the outcome of work efficiency is satisfaction. Platis, Reklitis, and Zimeras (2015) analyzed employee satisfaction and efficiency and identified that work satisfaction provides workers with feedback for improved performance. Better worker efficiency is the degree of employee satisfaction (Shah \& Jumani, 2015). The significant EP metrics at the recruiting level were studied by (Muntazeri \& Indrayanto, 2018). They concluded the degree of JS and motivation influences the employee's productivity. The low level of JS negatively impacts employee motivation and sequentially affects the accomplishment of corporate goals and results (NATH \& Agrawal, 2015)

H6: Job satisfaction positively impacts employee performance.

\section{The mediation role of organizational commitment}

Previous studies have linked EE and OC (Anindita \& Seda, 2018; Hanaysha, 2016a; Khalid \& Khalid, 2015; W. H. Putri \& Setianan, 2019) and WE to OC (Badrianto \& Ekhsan, 2020; Imran et al., 2012; Nguyen et al., 2015; Rorong, 2016). Also, OC is a critical factor in influencing EP, resulting in high organizational performance. Cesário and Chambel (2017) have linked OC and EP and found a significant link between the two variables. Yuniarti and Prasetyaningtyas (2020), through OC, there is a positive connection between EE and EP. This is because dedicated workers feel positive feelings that extend their thought, allowing them to become more attentive and immersed in their job. Building on these, the present study theorizes that EE and WE can be associated with higher OC levels, resulting in a higher level of EP. 
H7: Organizational commitment mediates the connection between employee engagement and employee performance.

H8: Organizational commitment mediates the link between work environment and employee performance.

\section{The Moderating Role of Job Satisfaction}

Employees search for jobs and pursue organizations with unique goals and expectations (i.e., money, comfort, personal growth, learning, etc.). Employees tend to be happy with their performance as reality meets expectations. Satisfaction thereby encompasses employee behaviors linked to jobs (Chaudhary, Bidlan, \& Darolia, 2015). A widely theorized EP measure is the level of JS (Al-Ali, Ameen, Isaac, Khalifa, \& Shibami, 2019; Inuwa, 2016). EE was linked with high OC (Hanaysha, 2016b) and JS (Abraham, 2012; Thakur, 2014; Vorina, Simonič, \& Vlasova, 2017). Also, WE have been significantly linked with OC (Abdullah \& Ramay, 2012; Ahakwa, Yang, Tackie, Odai, et al., 2021; Hanaysha, 2016a; Khuong \& Le Vu, 2014; Vanaki \& Vagharseyyedin, 2009) and job satisfaction (Agbozo, Owusu, Hoedoafia, \& Atakorah, 2017; Raziq \& Maulabakhsh, 2015) OC exerted a significant EP (Syauta, Troena, \& Margono Setiawan, 2012). (Pohler \& Schmidt, 2016) also linked commitment and satisfaction. The link between OC and JS has been widely acknowledged (Eslami \& Gharakhani, 2012; Kirk-Brown \& Van Dijk, 2016; Rusu, 2013). In this view, we contend that JS can strengthen these associations, such that higher levels of JS would strengthen the effect of WE and EE on OC, thus increases EP.

H9: Job satisfaction moderates the association amid employee engagement and organizational commitment.

H10: Job satisfaction moderates the nexus amid work environment and organizational commitment.

H11: Organizational commitment will mediate the relationship between employee engagement and employee performance, and the association will be stronger when job satisfaction is high.

H12: Organizational commitment will mediate the link between work environment and employee performance, and the association will be stronger when job satisfaction is high.

\section{The Conceptual Framework}

Based on the literature reviewed, the conceptual framework for this study is presented below.

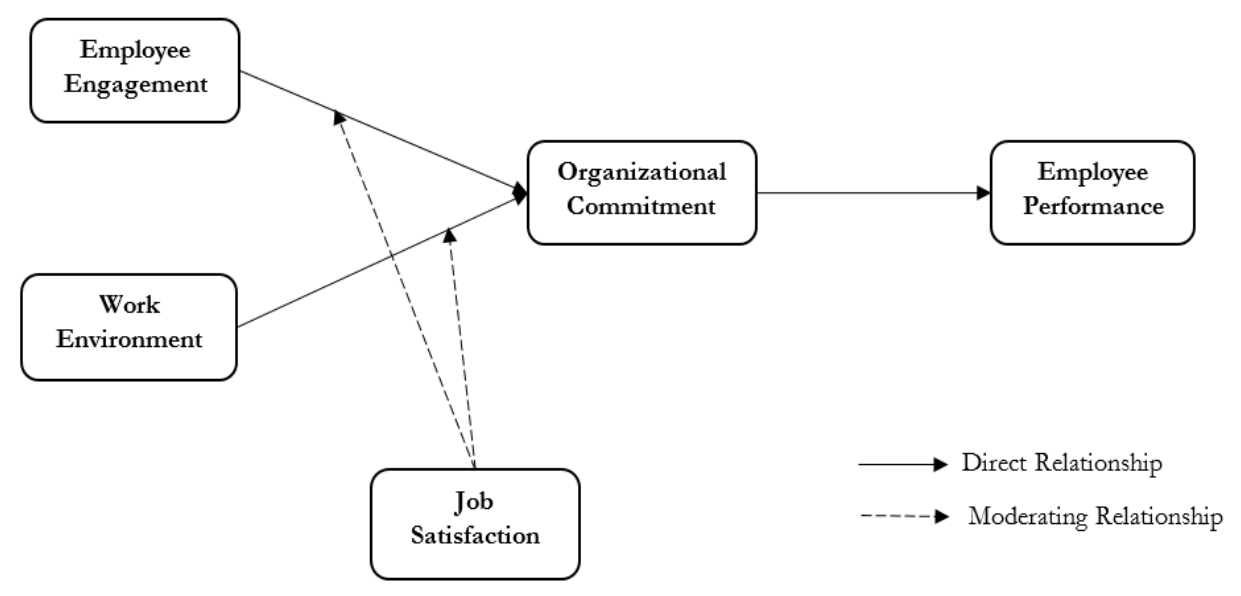

Figure 1: The Conceptual Framework 


\section{Methods}

\section{Research Design}

A research design is a collection of procedures and techniques used to capture and analyze the measurements of factors recognized in a research problem (Ahakwa, Yang, Tackie, \& Bankole, 2021). To evaluate classification features, quantify numbers, and construct a predictive pattern to test hypotheses and explain results, the research used quantitative approaches.

\section{Target Population}

The population is defined as a category of the research object, has one or more common characteristics, and is the subject of interest to the investigator. Employees and supervisors from Ghana Commercial Banks (GCB), Ecobank Ghana (EBG), Zenith Bank of Ghana, and Agricultural Development Bank (ADB) in the Greater Accra Metropolis were used as the study's population.

\section{Research sampling and sample size.}

The sampling applies to an approach to choosing a part of the sample population that will represent the whole study population. This research followed a simple random sampling technique where every employee was given an equal opportunity to answer the questions asked. The sample size used for the analysis was seven hundred (700), all of whom were employees from the Greater Accra Metropolis banking sector.

\section{Data instrument and collection}

To achieve the objectives of the study, the researcher gathered information from the study population. The research used the questionnaire as a medium to request information from the population. The questionnaire included questions related to the participants' demographic characteristics. There were questions in the second part of the questionnaire that helped examine the variables to be evaluated. Participants were called upon to rate the items based on the 5-point Likert with the scaling pole ranging from strongly disagree (1) to strongly agree (5). Seven hundred and twenty (720) online questionnaires were sent to respondents through various digital platforms. Seven hundred (700) were deemed fit and accurate, then used for discussion.

\section{Measurement of Variables}

OC was measured with eight items adapted from (Allen \& Meyer, 1996), and EP was measured with six items taken from (Cropanzano, Rupp, \& Byrne, 2003; Lutwama, 2011). Also, EE and WE were measured with four items, each adapted from (Hanaysha, 2016). Last, JS was also measured with four items adapted from (Clack 2020). All the items were measured on a scale of 1 to 5. Table 1 reveals the items used for each variable.

Table 1: Measurement of Variables

\begin{tabular}{ccl}
\hline Constructs & Indicator & Measurement Items \\
\hline Employee & EE1 & I feel energetic to do my job at this organization. \\
Engagement & EE2 & I find the work that I do full of meaning and purpose. \\
& EE3 & I am enthusiastic about my job. \\
Work Environment & EE4 & I can proceed to work for a very long period at a time. \\
& WE1 & My work environment is beautiful and visually attractive. \\
& WE3 & There is sufficient space amid my nearest co-worker and me. \\
& WE4 & I am satisfied with the space allocated for me to do my work. \\
Job Satisfaction & JS1 & I am rewarded for my dedication and commitment toward work. \\
& JS2 & My opinions are heard and valued by your superior(s) \\
& JS3 & My team provide support at work whenever I needed it \\
& JS4 & I do not struggle to get information to make better decisions at work \\
\hline
\end{tabular}




\begin{tabular}{cll}
\hline Employee & EP1 & I managed to plan my work so that it's done on time. \\
Performance & EP2 & I kept looking for new challenges in my job \\
& EP3 & I took on extra responsibilities. \\
EP4 & I took on challenging work tasks when available. \\
EP5 & I actively participated in work meetings. \\
& EP6 & I focused on the positive aspects of a work situation instead of on the \\
& OC1 & I wative aspects. \\
Organizational & OC2 & I do not feel a strong sense of belonging to this organization. \\
Commitment & OC3 & It would be very hard for me to leave my job at this organization. \\
& OC4 & I am proud to tell others that I am part of this institution \\
& OC5 & I am willing to put in high effort to help this institution be successful. \\
& OC6 & This organization deserves my loyalty. \\
& OC7 & For me, this is one of the best institutions for which to work. \\
& OC8 & I would feel guilty if I left this organization now \\
\hline
\end{tabular}

\section{Data Analysis}

The research involved exploratory and confirmatory studies in confirming the validity of the model. SPSS version 26.0 was used to process descriptive statistics to measure the demographic profile of the samples. Partial Least Squares (PLS) analysis using SmartPLS 3.0 software was used to evaluate the research model. The measurement model was tested for validity and reliability of the constructs using both the PLS-SEM algorithm and WPLS-SEM algorithm. The structural model was then analyzed in conjunction with the two-stage analytical procedures suggested for SEM (Hair Jr et al., 2016). We used both PLS-SEM and WPLS-SEM to looked at the $\mathrm{R}^{2}$, path coefficient $(\beta)$, and corresponding t-statistics through the 5000 resample bootstrapping process suggested by Hair Jr et al. (2016). They also recommended that researchers report on predictive significance $\left(\mathrm{Q}^{2}\right)$ and effect sizes $\left(\mathrm{f}^{2}\right)$ together with the basic measures. We also looked at assessing the prediction error degree using PLSpredict as recommended by (Shmueli et al., 2019).

\section{Empirical Results}

Table 2: Age $e^{*}$ Gender cross-tabulation

\begin{tabular}{|c|c|c|c|c|c|}
\hline \multirow[b]{3}{*}{ Age } & \multirow[b]{3}{*}{$15-24$} & \multirow[b]{3}{*}{ Counts } & \multicolumn{2}{|c|}{ Gender } & \multirow[t]{2}{*}{ Total } \\
\hline & & & Male & Female & \\
\hline & & & 10 & 187 & 197 \\
\hline & & $\%$ within Age & $5.08 \%$ & $94.92 \%$ & $100 \%$ \\
\hline & & $\%$ within Gender & $16.95 \%$ & $29.17 \%$ & $46.12 \%$ \\
\hline & $25-34$ & Counts & 27 & 284 & 311 \\
\hline & & \% within Age & $8.68 \%$ & $91.32 \%$ & $100 \%$ \\
\hline & & $\%$ within Gender & $45.76 \%$ & $44.31 \%$ & $90.07 \%$ \\
\hline \multirow{6}{*}{ Total } & $35-54$ & Counts & 22 & 170 & 192 \\
\hline & & $\%$ within Age & $11.46 \%$ & $88.54 \%$ & $100 \%$ \\
\hline & & $\%$ within Gender & $37.29 \%$ & $26.52 \%$ & $63.81 \%$ \\
\hline & & Counts & 59 & 641 & 700 \\
\hline & & \% within Age & $8.43 \%$ & $91.57 \%$ & $100 \%$ \\
\hline & & $\%$ within Gender & $100 \%$ & $100 \%$ & $100 \%$ \\
\hline
\end{tabular}

Table 2 reveals that for each age distribution, more females responded to the questionnaire than males. For each group, 15-24, 187 females representing 94.92\% answered the items compared to 10 males representing $5.08 \%$. Also, age group 25-34 had $284(91.32 \%)$ females and $27(8.68 \%)$ males responding to this study's items. Last, 35-54 age groups had $170(88.54 \%)$ females and 59 (8.43\%) males responding to this study's items. Overall, 
females representing $91.57 \%$ (641), and males representing $8.43 \%$ (59). This indicates that more females responded to the items than males. The finding, therefore, reveals that more females than males dominate the banking sector of Ghana. Hence researchers' decided to apply weight to each observation to have an accurate representative sample.

Table 3: Post-stratification weights of IndexMundi

\begin{tabular}{ccccccc}
\hline Age & Gender & $\begin{array}{c}\text { Sample } \\
\text { (n) }\end{array}$ & $\begin{array}{c}\text { Proportion of } \\
\text { samples (PS) }\end{array}$ & $\begin{array}{c}\text { Population } \\
\text { (N) }\end{array}$ & $\begin{array}{c}\text { Proportion of } \\
\text { population (PP) }\end{array}$ & $\begin{array}{c}\text { Weight } \\
\text { (PP/PS) }\end{array}$ \\
\hline $\mathbf{1 5 - 2 4}$ & male & 10 & 0.014285714 & 2717481 & 0.175050016 & 12.254 \\
$\mathbf{1 5 - 2 4}$ & female & 187 & 0.267142857 & 2752601 & 0.177312316 & 0.664 \\
$\mathbf{2 5 - 3 4}$ & male & 27 & 0.038571429 & 2841782 & 0.183057024 & 4.746 \\
$\mathbf{2 5 - 3 4}$ & female & 284 & 0.405714286 & 2186345 & 0.140836211 & 0.347 \\
$\mathbf{3 5 - 5 4}$ & male & 22 & 0.031428571 & 2034203 & 0.131035789 & 4.169 \\
$\mathbf{3 5 - 5 4}$ & female & 170 & 0.242857143 & 2991614 & 0.192708644 & 0.794 \\
Total & & 700 & & 15524026 & & \\
\hline
\end{tabular}

Table 4: SPSS syntax

IF (age $=1$ AND gender $=1$ ) weight $=12.254$.

IF (age $=1$ AND gender $=2$ ) weight $=0.664$.

IF (age $=2$ AND gender $=1$ ) weight $=4.746$.

IF (age $=2$ AND gender $=2$ ) weight $=0.347$.

IF (age $=3$ AND gender $=1$ ) weight $=4.169$.

IF (age $=3$ AND gender $=2$ ) weight $=0.794$.

EXE.

Age and gender distribution of the population of IndexMundi on the Ghana Demographics Profile (www.indexmundi.com) was collected to compute each observation's sampling weight. We first separately used the populations of the age group and gender parted by the population to measure the proportion of the population. Next, we used each group sample separated by the sample's sum to produce 'Sample Proportion.' Finally, we obtained the 'Weight' group findings on the 'Population Proportion' being split by the 'Sample Proportion.' Table 3 compares the age and gender survey and demographic distributions. Next, using the values described in Table3, we produced a weighting variable. For example, Table 4 uses the values described in Table 3 to display the syntax commands for producing the weighting variable. In the syntax, the collections of observations whose sampling weights requisite adjustment are identified by age and gender, while weight defines the weighting variable.

Table 5 displays the reflective measurement model for both PLS-SEM and WPLS-SEM for internal consistency reliability, convergent, and discriminant validity. The indicator loadings, average variance extracted (AVE), composite reliability (CR), and Cronbach alpha (CA) values of the latent constructs were extracted after performing the confirmatory factor analysis on all the constructs. In both PLS-SEM and WPLS-SEM models, the indicator loadings were above 0.6 as recommended by (Chin, Peterson, \& Brown, 2008). The indicator loadings for both PLS-SEM and WPLS-SEM ranged from 0.616-0.953 and 0.638-0.960, respectively. The Cronbach alpha for WPLS-SEM ranged from 0.773-0.939, and for PLS-SEM ranged from 0.763-0.963; thus, both PLS-SEM and WPLS-SEM met the suggested threshold of above 0.7 (Hair Jr et al., 2016). Moreover, we test for the CR of all the constructs, and the value ranged from 0.796-0.948, exceeding the suggested figure of 0.7 or greater (Hair Jr et al., 2016), with OC bearing the highest value in the WPLS-SEM. In the PLS-SEM model, CR ranged from 0.846-0.969, exceeding the suggested figure of 0.7 or greater (Hair Jr et al., 2016), with OC bearing the highest value. 
Table 5: Construct Reliability and Validity

\begin{tabular}{|c|c|c|c|c|c|c|}
\hline Model & Constructs & Indicators & $\begin{array}{l}\text { Indicator Loading } \\
\quad(\geq 0.60)\end{array}$ & $\begin{array}{c}\text { Cronbach } \\
\text { Alpha }(\geq 0.70)\end{array}$ & $\begin{array}{c}\text { Composite } \\
\text { Reliability }(\geq 0.70)\end{array}$ & $\begin{array}{c}\text { AVE } \\
(\geq 0.50)\end{array}$ \\
\hline \multirow[t]{26}{*}{ PLS-SEM } & \multirow[t]{4}{*}{$\mathrm{EE}$} & EE1 & 0.821 & \multirow[t]{4}{*}{0.763} & \multirow[t]{4}{*}{0.846} & \multirow[t]{4}{*}{0.581} \\
\hline & & EE2 & 0.743 & & & \\
\hline & & EE3 & 0.792 & & & \\
\hline & & EE4 & 0.685 & & & \\
\hline & \multirow[t]{6}{*}{ EP } & EP1 & 0.773 & \multirow[t]{6}{*}{0.896} & \multirow[t]{6}{*}{0.917} & \multirow[t]{6}{*}{0.650} \\
\hline & & EP2 & 0.862 & & & \\
\hline & & EP3 & 0.858 & & & \\
\hline & & EP4 & 0.766 & & & \\
\hline & & EP5 & 0.801 & & & \\
\hline & & EP6 & 0.770 & & & \\
\hline & \multirow{4}{*}{ JS } & JS1 & 0.750 & \multirow{4}{*}{0.883} & \multirow{4}{*}{0.920} & \multirow{4}{*}{0.744} \\
\hline & & JS2 & 0.910 & & & \\
\hline & & JS3 & 0.870 & & & \\
\hline & & JS4 & 0.911 & & & \\
\hline & \multirow{8}{*}{ OC } & OC1 & 0.827 & \multirow[t]{8}{*}{0.963} & \multirow[t]{8}{*}{0.969} & \multirow[t]{8}{*}{0.798} \\
\hline & & OC2 & 0.893 & & & \\
\hline & & OC3 & 0.914 & & & \\
\hline & & OC4 & 0.953 & & & \\
\hline & & OC5 & 0.949 & & & \\
\hline & & OC6 & 0.752 & & & \\
\hline & & OC7 & 0.951 & & & \\
\hline & & OC8 & 0.889 & & & \\
\hline & \multirow[t]{4}{*}{ WE } & WE1 & 0.848 & \multirow[t]{4}{*}{0.782} & 0.854 & 0.599 \\
\hline & & WE2 & 0.718 & & & \\
\hline & & WE3 & 0.883 & & & \\
\hline & & WE4 & 0.616 & & & \\
\hline WPLS-SEM & $\mathrm{EE}$ & EE1 & 0.834 & 0.789 & 0.859 & 0.561 \\
\hline & & EE2 & 0.708 & & & \\
\hline & & EE3 & 0.723 & & & \\
\hline & & EE4 & 0.852 & & & \\
\hline & EP & EP1 & 0.638 & 0.836 & 0.873 & 0.536 \\
\hline & & EP2 & 0.806 & & & \\
\hline & & EP3 & 0.835 & & & \\
\hline & & EP4 & 0.690 & & & \\
\hline & & EP5 & 0.700 & & & \\
\hline & & EP6 & 0.706 & & & \\
\hline & JS & JS1 & 0.666 & 0.869 & 0.909 & 0.717 \\
\hline & & JS2 & 0.925 & & & \\
\hline & & JS3 & 0.844 & & & \\
\hline & & JS4 & 0.926 & & & \\
\hline & OC & OC1 & 0.778 & 0.939 & 0.948 & 0.660 \\
\hline & & OC2 & 0.820 & & & \\
\hline & & OC3 & 0.860 & & & \\
\hline & & OC4 & 0.882 & & & \\
\hline & & OC5 & 0.878 & & & \\
\hline & & OC6 & 0.895 & & & \\
\hline & & OC7 & 0.905 & & & \\
\hline & & OC8 & 0.820 & & & \\
\hline & WE & WE1 & 0.820 & 0.773 & 0.796 & 0.504 \\
\hline & & WE2 & 0.960 & & & \\
\hline & & WE3 & 0.849 & & & \\
\hline & & WE4 & 0.892 & & & \\
\hline
\end{tabular}


All the constructs in both PLS-SEM and WPLS-SEM met the AVE's minimum required value of 0.5, as suggested by (Hair Jr et al., 2016). AVE's values for EE, EP, JS, OC and WE are 0.561, 0.536, 0.717, 0.660 and 0.504 respectively in the WPLS-SEM model. Likewise for PLS-SEM model, AVE's figures for EE, EP, JS, OC and WE are $0.581,0.650,0.744,0.798$ and 0.599 respectively. Having met the above minimum threshold requirements proposed by (Hair Jr et al., 2016) and (Chin et al., 2008) for the internal consistency and reliability checks, we can conclude that the model is accurate enough for the analysis in both WPLS-SEM and PLS-SEM.

Table 6: Collinearity Value Assessed by Outer VIF

\begin{tabular}{ccccc}
\hline \multirow{2}{*}{ Constructs } & \multicolumn{2}{c}{ PLS-SEM } & \multicolumn{2}{c}{ WPLS-SEM } \\
\cline { 2 - 4 } EE & Indicators & VIF Values & Indicators & VIF Values \\
& EE1 & 1.567 & EE1 & 1.476 \\
EE2 & 1.421 & EE2 & 1.365 \\
EE3 & 1.710 & EE3 & 1.236 \\
EE4 & 1.544 & EE4 & 1.160 \\
EP1 & 2.541 & EP1 & 2.272 \\
EP2 & 2.978 & EP2 & 2.127 \\
EP & EP3 & 2.722 & EP3 & 2.017 \\
& EP4 & 1.598 & EP4 & 3.069 \\
& EP5 & 3.058 & EP5 & 2.909 \\
& EP6 & 2.570 & EP6 & 2.005 \\
JS1 & 1.581 & JS2 & 1.297 \\
& JS2 & 2.693 & JS3 & 1.258 \\
& JS3 & 2.308 & JS4 & 1.966 \\
& JS4 & 3.254 & OC1 & 2.347 \\
& OC1 & 3.165 & OC2 & 2.374 \\
& OC2 & OC3 & 3.824 \\
OC3 & 3.161 & OC4 & 1.358 \\
& OC4 & 1.662 & OC5 & 2.159 \\
& OC5 & 2.211 & OC6 & 1.681 \\
& OC6 & 1.365 & OC7 & 2.983 \\
& OC7 & 2.535 & OC8 & 2.969 \\
& OC8 & 3.214 & WE1 & 1.735 \\
& WE1 & 2.368 & WE2 & 1.328 \\
& WE2 & 2.111 & WE4 & 1.578 \\
& WE3 & 1.647 & 1.850 & 1.261 \\
\hline
\end{tabular}

Note: EE=Employee Engagement; JS=Job Satisfaction; WE=Work Environment; OC=Organizational Commitment; WE $=$ Work Environment.

Table 7: Collinearity Value Assessed by VIF (Inner Values)

\begin{tabular}{llclc}
\hline \multirow{2}{*}{ Variables } & \multicolumn{3}{c}{ PLS-SEM } & WPLS-SEM \\
\cline { 2 - 5 } EE & EP & OC & EE & OC \\
JS & 1.527 & 1.437 & 1.785 & 1.258 \\
OC & 1.771 & 1.413 & 1.319 & 1.520 \\
WE & 1.967 & - & 1.876 & - \\
\hline
\end{tabular}

Tables 6 and 7 present the VIFs (outer values and inner values) assessments of the various constructs' collinearity values. To better understand collinearity in the statistical model, Dormann et al. (2013) state that it 
is used to estimate the linkage amid a dependent variable and a group of independent (predictor) variables. Grewal, Cote, and Baumgartner (2004) argue that the collinearity problem among variables may occur just by chance, especially when the sample size used for the analysis is low. However, perfect collinearity can arise if all the variables used in the study are of the same linear qualities (Dormann et al., 2013). According to J. H. Kim (2019), if the VIF figures are more than 5, there is a collinearity problem in the model. However, if the VIF figures are lower than 5, then the model is free from the problem of collinearity. Our VIF assessment for both PLS-SEM and WPLS-SEM revealed values less than five (5), suggesting no collinearity problems in the model (Tackie et al., 2020).

Also, the occurrence of a VIF greater than 3.3 is proposed as an indication of pathological collinearity and indicates that the model may be contaminated by common method bias. Therefore, if all VIFs resulting from a full collinearity test are equal to or lower than 3.3, the model can be considered free from common method bias (Kock, 2015). Hence our VIFs (outer and inner values) in both PLS-SEM and WPLS-SEM as presented in Tables 6 and 7 suggest that our model is free from CMB.

Table 8: Fornell-Larcker Discriminant Validity

\begin{tabular}{lllllllllll}
\hline Latent Variables & \multicolumn{4}{l}{ PLS-SEM } & \multicolumn{9}{l}{ WPLS-SEM } \\
& EE & EP & JS & OC & WE & EE & EP & JS & OC & WE \\
EE & $\mathbf{0 . 7 6 2}$ & & & & & $\mathbf{0 . 7 0 0}$ & & & & \\
EP & 0.546 & $\mathbf{0 . 8 0 6}$ & & & & 0.519 & $\mathbf{0 . 7 3 2}$ & & & \\
JS & 0.495 & 0.551 & $\mathbf{0 . 8 6 3}$ & & & 0.512 & 0.524 & $\mathbf{0 . 8 4 7}$ & & \\
OC & 0.471 & 0.549 & 0.673 & $\mathbf{0 . 8 9 3}$ & & 0.522 & 0.574 & 0.622 & $\mathbf{0 . 8 1 2}$ & \\
WE & 0.334 & 0.388 & 0.316 & 0.368 & $\mathbf{0 . 7 7 4}$ & 0.372 & 0.381 & 0.352 & 0.472 & $\mathbf{0 . 7 1 0}$ \\
\hline
\end{tabular}

To weigh the discriminant validity, which represents the degree to which the measures are not replicating some other variables, low correlations between the measure of interest and other constructs' measures are indicated. Table 8 shows that each construct's AVE square root (diagonal values) is greater than its corresponding correlation coefficients, suggesting sufficient discriminant validity (Fornell \& Larcker, 1981) in the PLS-SEM and WPLS-SEM.

Table 9: Heterotrait-Monotrait Ratio (HTMT) for Discriminant V alidity

\begin{tabular}{|c|c|c|c|c|c|c|c|c|c|c|}
\hline \multirow{2}{*}{ Latent Variables } & \multirow[b]{2}{*}{ EE } & \multicolumn{3}{|c|}{ PLS-SEM } & \multirow[b]{2}{*}{ WE } & \multirow[b]{2}{*}{ EE } & \multicolumn{3}{|c|}{ WPLS-SEM } & \multirow[b]{2}{*}{ WE } \\
\hline & & EP & JS & OC & & & EP & JS & OC & \\
\hline EE & & & & & & & & & & \\
\hline EP & 0.625 & & & & & 0.639 & & & & \\
\hline JS & 0.567 & 0.557 & & & & 0.599 & 0.522 & & & \\
\hline OC & 0.519 & 0.552 & 0.722 & & & 0.595 & 0.598 & 0.674 & & \\
\hline WE & 0.379 & 0.441 & 0.310 & 0.384 & & 0.493 & 0.530 & 0.420 & 0.570 & \\
\hline
\end{tabular}

We also used the Heterotrait-Monotrait (HTMT) criterion to measure discriminant validity. Compared with Fornell-Larcker's Criterion, the HTMT gives a more rigorous outcome. (Henseler, Ringle, \& Sarstedt, 2015) debunked Fornell-Larcker Criterion because the researchers believed that it is not reliable enough to distinguish lack of discriminant validity in ordinary research. Therefore, a multitrait-multimethod matrix analysis tool; thus, the HTMT ratio of correlations is considered more reliable. Table 9 gives the values for the discriminant validity measured using the Henseler et al. (2015) alternative approach. According to (Kline, 2011) when the HTMT value is larger than the threshold figure of 0.85 , there is a problem with discriminant validity. However, as presented in Table 9, the discriminant figures for all the constructs (EE, WE, JS, OC, and EP) were below the 
HTMT threshold value of 0.85 in the PLS-SEM and WPLS-SEM. Therefore, using the Heterotrait- Monotrait criterion, our analysis is free from discriminant validity problems (Kline, 2011) in PLS-SEM and WPLS-SEM.

\section{Assessment of the Structural Model}

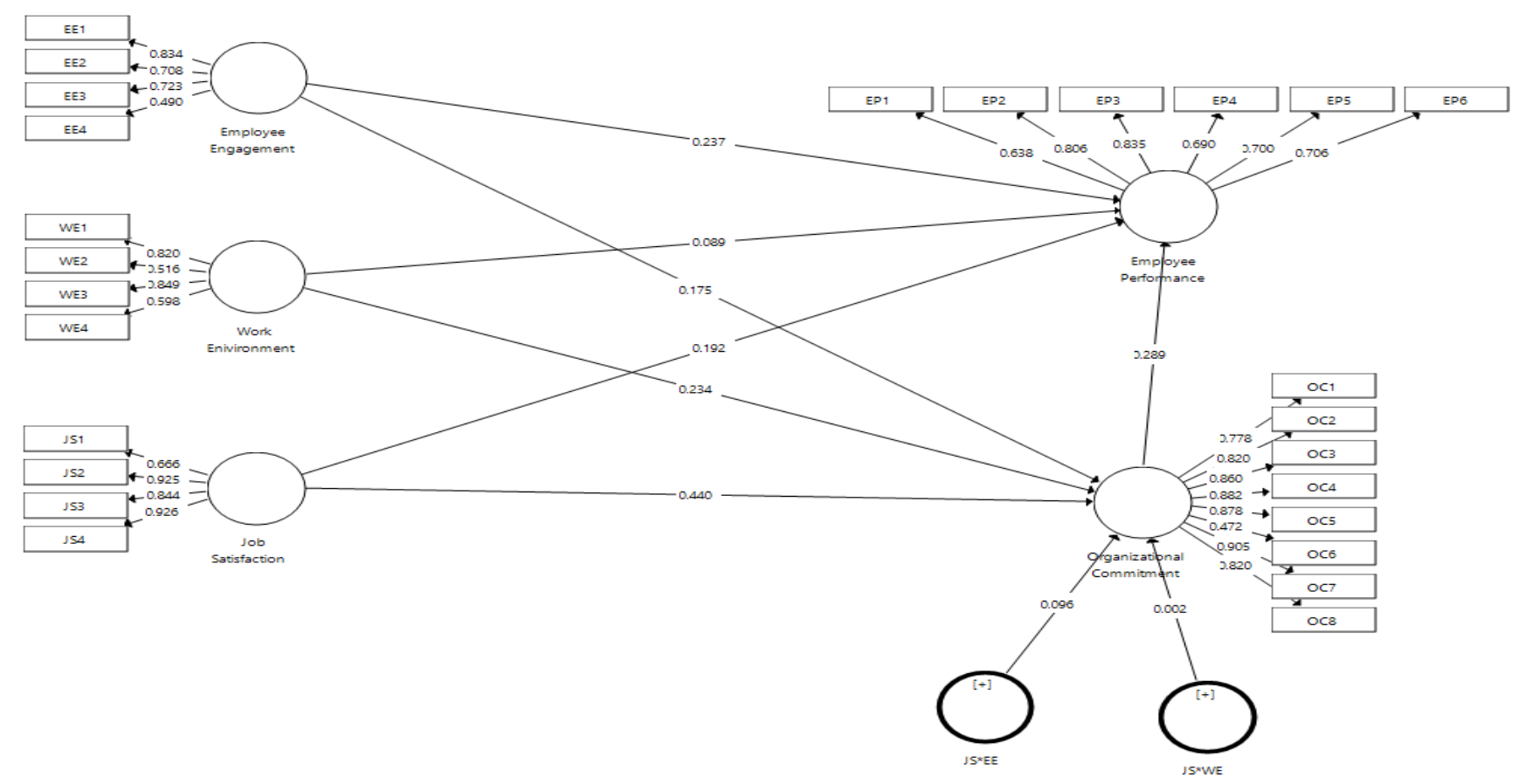

Figure 2: The Structural Model (PLS-SEM)

Table 10: Hypotheses testing (Direct Relationship)

\begin{tabular}{|c|c|c|c|c|c|}
\hline Model & Hypotheses & Path Co-efficient $(\beta)$ & t-value & p-value & Decision \\
\hline \multirow[t]{6}{*}{ PLS-SEM } & $\mathrm{H} 1: \mathrm{EE} \rightarrow \mathrm{OC}$ & 0.148 & 4.170 & $0.000^{a}$ & Supported \\
\hline & $\mathrm{H} 2: \mathrm{EE} \rightarrow \mathrm{EP}$ & 0.321 & 8.906 & $0.000^{\mathrm{a}}$ & Supported \\
\hline & H3: WE $\rightarrow$ OC & 0.143 & 4.362 & $0.000^{\mathrm{a}}$ & Supported \\
\hline & $\mathrm{H} 4: \mathrm{WE} \rightarrow \mathrm{EP}$ & 0.174 & 5.387 & $0.000^{\mathrm{a}}$ & Supported \\
\hline & H5: OC $\rightarrow$ EP & 0.211 & 4.454 & $0.000^{\mathrm{a}}$ & Supported \\
\hline & H6: JS $\rightarrow$ EP & 0.338 & 10.134 & $0.000^{\mathrm{a}}$ & Supported \\
\hline \multirow[t]{6}{*}{ WPLS-SEM } & $\mathrm{H} 1: \mathrm{EE} \rightarrow \mathrm{OC}$ & 0.214 & 4.285 & $0.000^{\mathrm{a}}$ & Supported \\
\hline & $\mathrm{H} 2: \mathrm{EE} \rightarrow \mathrm{EP}$ & 0.298 & 5.406 & $0.000^{\mathrm{a}}$ & Supported \\
\hline & H3: WE $\rightarrow$ OC & 0.243 & 3.951 & $0.000^{\mathrm{a}}$ & Supported \\
\hline & H4: WE $\rightarrow$ EP & 0.131 & 1.538 & $0.124^{b}$ & Unsupported \\
\hline & H5: OC $\rightarrow$ EP & 0.289 & 4.353 & $0.000^{\mathrm{a}}$ & Supported \\
\hline & H6: JS $\rightarrow$ EP & 0.316 & 4.647 & $0.000^{\mathrm{a}}$ & Supported \\
\hline
\end{tabular}

${ }^{\mathrm{a}},{ }^{\mathrm{b}}$ Indicate significance at the $1 \%$ and the $5 \%$ levels, respectively; Critical t-value is 1.96

We assessed the direct relationships in the study's model. Table 10 reveals, first H1 [EE $\rightarrow$ OC] in the PLSSEM and WPLS-SEM; is supported $(\beta=0.148$; $\mathrm{t}$-value $=4.170, \mathrm{p}<0.01)$ and $(\beta=0.214 ; \mathrm{t}$-value $=4.285, \mathrm{p}<0.01)$ respectively. This finding indicates that EE positively and significantly influence OC. Second, H2 [EE $\rightarrow$ EP] in the PLS-SEM and WPLS-SEM; is supported $(\beta=0.321 ; \mathrm{t}$-value $=8.906, \mathrm{p}<0.01)$ and $(\beta=0.298 ; \mathrm{t}-\mathrm{value}=5.406$, $\mathrm{p}<0.01)$ respectively. This finding implies that EE positively and significantly influence EP. Third, H3 [WE 
$\rightarrow \mathrm{OC}]$ in the WPLS-SEM and PLS-SEM; is supported $(\beta=0.243$; $\mathrm{t}$-value=3.951, $\mathrm{p}<0.01)$ and $(\beta=0.143$; $\mathrm{t}$ value $=4.362, \mathrm{p}<0.01)$ respectively. This finding denotes that WE positively and significantly influence OC. Fourth, H4 [WE $\rightarrow$ EP] in the WPLS-SEM is unsupported $(\beta=0.131$; $t$-value $=1.538, p<0.05)$, however, H4 $[\mathrm{WE} \rightarrow \mathrm{EP}]$ in the PLS-SEM is supported $(\beta=0.174$; $\mathrm{t}$-value $=5.387, \mathrm{p}<0.01)$. This finding suggests that WE positively and significantly influence EP in the PLS-SEM but does not in WPLS-SEM model. Fifth, H5 [OC $\rightarrow$ EP] in the PLS-SEM and WPLS-SEM; is supported $(\beta=0.211$; $t$-value $=4.454, p<0.01)$ and $(\beta=0.289$; $\mathrm{t}$ value $=4.353, \mathrm{p}<0.01)$ respectively. This finding infers that OC positively and significantly influence EP. Last, H6 [JS $\rightarrow$ EP] in the PLS-SEM and WPLS-SEM; is supported $(\beta=0.338$; $t$-value $=10.134, p<0.01)$ and $(\beta=0.316 ; \mathrm{t}-\mathrm{value}=4.647, \mathrm{p}<0.01)$ respectively. This finding reveals that JS positively and significantly influence EP.

Comparing the two models (WPLS-SEM and PLS-SEM), we discovered three path coefficients varying more than 0.05. First, in the WPLS-SEM, the path coefficient for EE $\rightarrow$ OC is 0.214 , and, in the PLS-SEM, the path coefficient is 0.148 . The variation is 0.066 . Second, the path coefficient for WE $\rightarrow$ OC varies by 0.100 amid the two models, with the WPLS-SEM path equal to 0.243 and that of PLS-SEM is 0.143. Third, the path coefficient for OC $\rightarrow$ EP in the WPLS-SEM is 0.289, and that of the PLS-SEM model is 0.211 . The difference is 0.078 . Finally, these relationships were all significant at $1 \%$ level in both the PLS-SEM and WPLS-SEM. The WPLS-SEM model has a larger path coefficient $(\beta)$ values than the PLS-SEM model, making the WPLS-SEM more preferred. However, all direct relationship in the PLS-SEM model was supported.

Table 11: Hypotheses testing (Indirect Relationship)

${ }^{a}$ Indicate significance at the $1 \%$ level; Critical t-value is 1.96

\begin{tabular}{|c|c|c|c|c|c|c|}
\hline Model & Hypotheses & Path Co-efficient $(\beta)$ & t-value & p-value & Decision & $\begin{array}{l}\text { Mediation } \\
\text { Type }\end{array}$ \\
\hline \multirow[t]{2}{*}{ PLS-SEM } & $\mathrm{H} 7: \mathrm{EE} \rightarrow \mathrm{OC} \rightarrow \mathrm{EP}$ & 0.031 & 3.219 & $0.001^{\mathrm{a}}$ & Supported & $\begin{array}{l}\text { Complementary } \\
\text { (partial } \\
\text { mediation) }\end{array}$ \\
\hline & $\mathrm{H} 8: \mathrm{WE} \rightarrow \mathrm{OC} \rightarrow \mathrm{EP}$ & 0.030 & 2.815 & $0.005^{\mathrm{a}}$ & Supported & $\begin{array}{l}\text { Complementary } \\
\text { (partial } \\
\text { mediation) }\end{array}$ \\
\hline \multirow[t]{2}{*}{ WPLS-SEM } & $\mathrm{H} 7: \mathrm{EE} \rightarrow \mathrm{OC} \rightarrow \mathrm{EP}$ & 0.062 & 2.945 & $0.003^{\mathrm{a}}$ & Supported & $\begin{array}{l}\text { Complementary } \\
\text { (partial } \\
\text { mediation) }\end{array}$ \\
\hline & H8: $\mathrm{WE} \rightarrow \mathrm{OC} \rightarrow \mathrm{EP}$ & 0.070 & 2.608 & $0.009^{a}$ & Supported & $\begin{array}{l}\text { Indirect only } \\
\text { (full mediation) }\end{array}$ \\
\hline
\end{tabular}

We assessed the indirect effect; thus, mediation analysis. First, table 11 reveals that $\mathrm{H} 7 \mathrm{EE} \rightarrow \mathrm{OC} \rightarrow \mathrm{EP}]$ in the PLS-SEM and WPLS-SEM; is supported $(\beta=0.031$; $\mathrm{t}$-value $=3.219, \mathrm{p}<0.01)$ and $(\beta=0.062$; $\mathrm{t}$-value $=2.945$, $\mathrm{p}<0.01)$ respectively. This finding indicates that OC positively and significantly mediates the association between EE and EP. Second, H8 [WE $\rightarrow$ OC $\rightarrow$ EP] in the PLS-SEM and WPLS-SEM; is supported $(\beta=0.030$; $\mathrm{t}$-value $=2.815, \mathrm{p}<0.01)$ and $(\beta=0.070 ; \mathrm{t}$-value $=2.608, \mathrm{p}<0.01)$ respectively. This finding implies that $\mathrm{OC}$ positively and significantly mediates the link between WE and EP.

Comparing the two models (WPLS-SEM and PLS-SEM). First, in the WPLS-SEM, the path coefficient for EE $\rightarrow$ OC $\rightarrow$ EP is 0.062 and, in the PLS-SEM, the path coefficient is 0.031 . The variation is 0.031 . Second, the path coefficient for $\mathrm{WE} \rightarrow \mathrm{OC} \rightarrow \mathrm{EP}$ varies by $0.040 \mathrm{amid}$ the two models, with the WPLS-SEM path equal to 0.070 and that of PLS-SEM is 0.030. Also, OC fully mediates WE $\rightarrow$ EP in the WPLS-SEM model as compared to PLS-SEM with partial mediation. Finally, these relationships were all significant at $1 \%$ level in both the PLS-SEM and WPLS-SEM. The WPLS-SEM model has larger path coefficient $(\beta)$ values and better mediates relationships than the PLS-SEM model, making the WPLS-SEM more preferred. 
Table 12: Hypotheses testing (moderating relationship)

\begin{tabular}{llllll}
\hline Model & Hypotheses & Path Co-efficient $(\boldsymbol{\beta})$ & t-value & p-value & Decision \\
\hline PLS-SEM & H9: JS*EE $\rightarrow$ OC & 0.072 & 2.977 & $0.003^{\mathrm{a}}$ & Supported \\
& H10: JS*WE $\rightarrow$ OC & -0.059 & 1.881 & $0.060^{\mathrm{b}}$ & Unsupported \\
& H11: JS*EE $\rightarrow$ OC $\rightarrow$ EP & 0.015 & 2.396 & $0.017^{\mathrm{b}}$ & Supported \\
& H12: JS*WE $\rightarrow$ OC $\rightarrow$ EP & -0.012 & 1.745 & $0.081^{\mathrm{b}}$ & Unsupported \\
\multirow{3}{*}{ WPLS-SEM } & 0.096 & 3.190 & $0.001^{\mathrm{a}}$ & Supported \\
& H9: JS*EE $\rightarrow$ OC & 0.002 & 0.055 & $0.956^{\mathrm{b}}$ & Unsupported \\
& H10: JS*WE $\rightarrow$ OC & 2.524 & $0.012^{\mathrm{b}}$ & Supported \\
& H11: JS*EE $\rightarrow$ OC $\rightarrow$ EP & 0.028 & 0.055 & $0.957^{\mathrm{b}}$ & Unsupported \\
\hline
\end{tabular}

a, b Indicate significance at the $1 \%$ and the $5 \%$ levels, respectively; Critical t-value is 1.96

We assessed the indirect effect; thus moderation analysis. First, table 12 reveals that $\mathrm{H} 9$ [JS*EE $\rightarrow$ OC] in the PLS-SEM and WPLS-SEM; is supported $(\beta=0.072 ; \mathrm{t}$-value $=2.977, \mathrm{p}<0.01)$ and $(\beta=0.096$; $\mathrm{t}$-value $=3.190, \mathrm{p}<$ $0.01)$ respectively. This finding indicates that JS positively and significantly moderates the connection between $\mathrm{EE}$ and OC. Second, H10 [JS*WE $\rightarrow$ OC] in the PLS-SEM and WPLS-SEM; is unsupported $(\beta=-0.059$; tvalue $=1.881, \mathrm{p}<0.05)$ and $(\beta=0.002 ; \mathrm{t}$-value $=0.055, \mathrm{p}<0.05)$ respectively. This finding implies that JS does not significantly moderates the link between WE and EP. Third, H11 [JS*EE $\rightarrow$ OC $\rightarrow$ EP] in PLS-SEM and WPLS-SEM; is supported $(\beta=0.015 ; \mathrm{t}$-value $=2.396, \mathrm{p}<0.05)$ and $(\beta=0.028 ; \mathrm{t}$-value $=2.524, \mathrm{p}<0.05)$ respectively. This finding indicates that JS positively and significantly moderates the connection between EE and OC resulting in high level of EP. Last, H12 [JS*WE $\rightarrow$ OC $\rightarrow$ EP] in the PLS-SEM and WPLS-SEM; is unsupported $(\beta=-0.012$; $\mathrm{t}$-value $=1.745, \mathrm{p}<0.05)$ and $(\beta=0.001 ; \mathrm{t}$-value $=0.055, \mathrm{p}<0.05)$ respectively. This finding infers that JS does not significantly moderates the link between WE and OC leading to low level of EP.

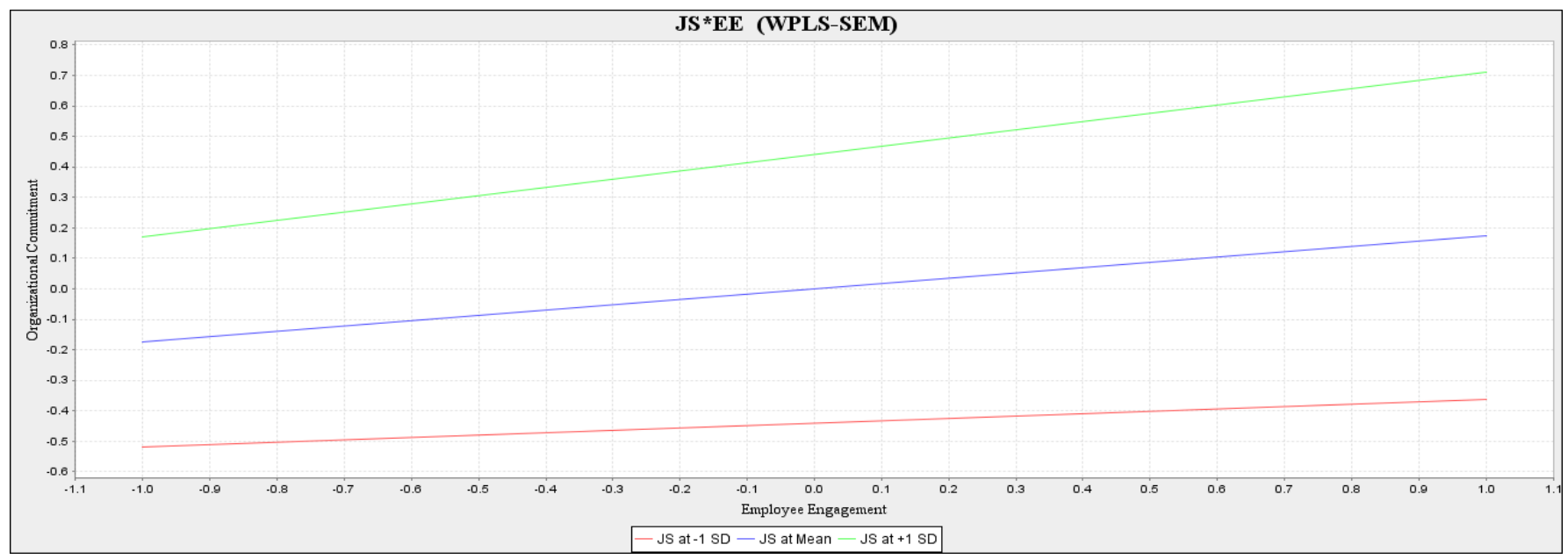

Figure 3: Interaction effect of JS on $E E$ and $O C$

Figures 3 and 4 reveal the interaction effect of JS on EE and OC in PLS-SEM and WPLS-SEM. The interaction reveals the significant effect of the moderating variable (JS) on EE and OC in both the PLS-SEM and WPLSSEM models. 


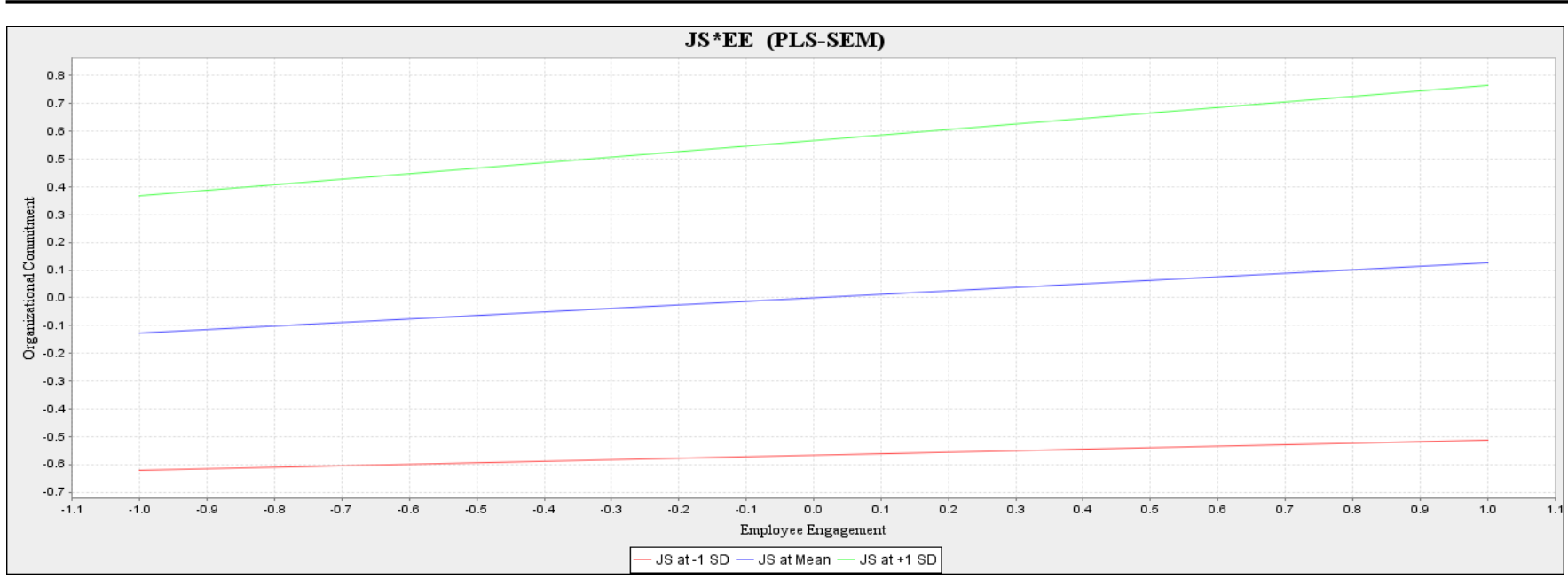

Figure 4: Interaction effect of JS on EE and OC

Table 13: Effect Size

\begin{tabular}{ccccc} 
Relationships & \multicolumn{2}{c}{ PLS-SEM } & \multicolumn{2}{c}{ WPLS-SEM } \\
\cline { 2 - 5 } $\mathbf{E E ~} \rightarrow$ OC & $\mathrm{f}$ square $\left(\mathrm{f}^{2}\right)$ & Effect Size & f square $\left(\mathrm{f}^{2}\right)$ & Effect Size \\
$\mathbf{E E ~} \rightarrow$ EP & 0.031 & Medium & 0.062 & Medium \\
$\mathbf{W E ~} \rightarrow$ OC & 0.106 & Medium & 0.064 & Medium \\
$\mathbf{W E ~} \rightarrow$ EP & 0.035 & Medium & 0.096 & Medium \\
$\mathbf{O C} \rightarrow$ EP & 0.031 & Medium & 0.016 & Medium \\
$\mathbf{J S} \rightarrow$ EP & 0.041 & Medium & 0.073 & Medium \\
$\mathbf{J S * E E ~} \rightarrow$ OC & 0.045 & Medium & 0.029 & Medium \\
JS*WE $\rightarrow$ OC & 0.009 & Small & 0.025 & Medium \\
\hline
\end{tabular}

Effect size measures the exogenous latent construct on the endogenous construct using the $\mathrm{f}^{2}$. Cohen (1988) guidelines were used to measure the effect size, which are 0.02 for small effects, 0.15 for medium effects, and 0.35 for large effects. Table 13 revealed that all relationships had a medium effect in the WPLS-SEM. All relationships had a medium effect in the PLS-SEM except [JS*EE $\rightarrow \mathrm{OC}$ ] and [JS*WE $\rightarrow \mathrm{OC}$ ] with small effects. The exogenous latent construct in the WPLS-SEM better influences the endogenous construct than that of the PLS-SEM.

Table 14: Predictive Relevance

\begin{tabular}{ccccccc}
\hline Constructs & \multicolumn{3}{c}{ PLS-SEM } & \multicolumn{3}{c}{ WPLS-SEM } \\
\cline { 2 - 6 } EP & R Square $\left(R^{2}\right)$ & Adjusted $R^{2}$ & Q square $\left(Q^{2}\right)$ & R Square $\left(R^{2}\right)$ & Adjusted $R^{2}$ & Q square $\left(Q^{2}\right)$ \\
OC & 0.451 & 0.448 & 0.261 & 0.423 & 0.420 & 0.193 \\
\hline
\end{tabular}

Table 14 discloses the $\mathrm{R}^{2}$, which is the total amount of explained variance in the endogenous constructs'. With the WPLS-SEM, the $\mathrm{R}^{2}$ figure of EP is 0.423 , whereas the $\mathrm{R}^{2}$ figure of OC is 0.506 . In the PLS-SEM, the $\mathrm{R}^{2}$ of EP and OC are 0.451 and 0.501, respectively. These outcomes signpost that when relating the two models (PLS-SEM and WPLS-SEM), the $\mathrm{R}^{2}$ of both endogenous constructs does not vary much in size.

Table 14 reveals the blindfolding procedure, which determines the predictive significance $\mathrm{Q}^{2}$ of PLS path models (Hair Jr et al., 2016). We acquired our $\mathrm{Q}^{2}$ figure through cross-validated redundancy procedures. A $\mathrm{Q}^{2}$ figure bigger than zero means that the model has predictive relevance; however, a $\mathrm{Q}^{2}$ figure beneath zero indicates the model's predictive significance lacks. For this assessment criterion, we also discovered a variation of more than 0.05 in the two models. In the PLS-SEM and WPLS-SEM, the $\mathrm{Q}^{2}$ figure of EP is 0.261 and 0.193 , 
respectively, leading to a variation of 0.068 . The variation amid the two model's $\mathrm{Q}^{2}$ figures of $\mathrm{OC}$ is 0.073 . With the WPLS-SEM, the $\mathrm{Q}^{2}$ figure of OC is 0.304 , while with PLS-SEM, the $\mathrm{Q}^{2}$ figure of OC is 0.377 . Both PLSSEM and WPLS-SEM model has predictive relevance; however, PLS-SEM better predicts the model's relevance.

Table 15: PLSpredict

\begin{tabular}{ccccc} 
PLSpredict & \multicolumn{2}{c}{ Organizational Commitment } & \multicolumn{2}{c}{ Employee Performance } \\
\cline { 2 - 5 } & WPLS-SEM & PLS-SEM & WPLS-SEM & PLS-SEM \\
RMSE & 0.547 & $\mathbf{0 . 5 4 6}$ & 0.548 & $\mathbf{0 . 4 9 2}$ \\
MAE & 0.414 & $\mathbf{0 . 4 0 6}$ & 0.430 & $\mathbf{0 . 3 8 6}$ \\
$\boldsymbol{Q}^{2}$ predict & 0.378 & $\mathbf{0 . 4 1 6}$ & 0.304 & $\mathbf{0 . 3 2 4}$ \\
\hline
\end{tabular}

Note: Bold means represents better result on its criterion; mean absolute error (MAE); root mean square error (RMSE)

We performed "PLSpredict" on the two models (Shmueli et al., 2019). Table 15 revealed that for both OC and EP constructs, the PLS-SEM study resulted in marginally lower prediction errors for both targets constructs given MAE and RMSE and high $\mathrm{Q}^{2}$ predict figure. Generally, our PLSpredict test showed that the model calculated using PLS-SEM matched the data better and realized a higher predictive power.

\section{Discussion}

Our study support and advance previous studies wherein EE significantly impact OC (Hanaysha, 2016a; Imam \& Shafique, 2014; Nazir \& Islam, 2017) and EP (Anitha, 2014; Ayub \& Islam, 2018; Sendawula et al., 2018). This outcome proposes that the more workers are engaged in the workplace, their commitment and performance to the establishment will be high. An employee who displays good working behavior by engagement is likely to express greater commitment and success to the company due to the great zeal and bravery for accomplishment, which justifies this study's finding (Schaufeli \& Bakker, 2004). The author further indicated that engaged workers appear to encourage meaningful interactions and efficiency in their organizations. Also, WE positively influence OC (Ahakwa, Yang, Tackie, Odai, et al., 2021; Hanaysha, 2016a; Khuong \& Le Vu, 2014) and EP (Badrianto \& Ekhsan, 2020; Imran et al., 2012; Nguyen et al., 2015; Rorong, 2016). This finding discloses that WE are a critical element that can impact employees' commitment and performance in an organization. Therefore, this result's practical implication suggests that authorities in charge of organizations have to be mindful of the value of creating a conducive environment by enhancing OC among their workforces, therefore leading to increased performance. For example, the provision of leisure facilities and preserving a green and sanitary environment can play a central role in coaxing employees' actions. Moreover, the outline of the workplace and organizational philosophy is also fundamental to enhance OC and performance.

Furthermore, JS positively contributes to previous studies by impacting EP (Chaudhry et al., 2017; Platis et al., 2015), and OC also positively influence EP (Hidayah \& Tobing, 2018; Susanty \& Miradipta, 2013). This result means that the presence of JS and OC in an establishment leads to improved EP. Individuals with a high degree of company loyalty and happiness can reflect the organization's good behavior, offer the best of their abilities, sacrifice, be faithful to the organization and still have a desire to stick with it. This implies that an individual with a high degree of OC and satisfaction aims to demonstrate high level of work performance. On the other hand, an individual with low level of organizational commitment and satisfaction tend to show no care and irresponsibility to the accomplishment of the work (low level of work performance). It is therefore crucial to regularly review employees' commitment and satisfaction to resolving any problems that may occur make sure that workers maintain a favorable attitude to work which is crucial for total organizational success.

Also, the finding supports our overarching proposition that OC will mediate the link between EE and EP. This is in line with the study conducted by Yuniarti and Prasetyaningtyas (2020), who indicated that through OC, 
there is a positive connection between EE and EP, and this is because dedicated workers feel positive feelings that extend their thought, allowing them to become more attentive and immersed in their job. Also, the finding supports our overarching proposition that OC will mediate the link between WE and EP. Existing empirical evidence show that WE have a positive correlativity with OC (Ahakwa, Yang, Tackie, Odai, et al., 2021; Hanaysha, 2016a; Khuong \& Le Vu, 2014) and positive correlativity with EP (Badrianto \& Ekhsan, 2020; Imran et al., 2012; Nguyen et al., 2015; Rorong, 2016). This implies that OC is the mechanism through which EE and WE use to increase EP. Implying that lack of EE and poor WE in one's organization and its presence in another organization serves as a push factor towards EP.

This study revealed that JS positively moderates the association between EE and OC. This is in line with previous research that found JS to positively influence EE (Chaudhry et al., 2017; Platis et al., 2015) and OC (Eslami \& Gharakhani, 2012; Kirk-Brown \& Van Dijk, 2016; Rusu, 2013). However, JS failed to moderate the connection between WE and OC. This study contradicts existing studies that found that JS positively affects WE (Agbozo et al., 2017; Raziq \& Maulabakhsh, 2015) and OC (Eslami \& Gharakhani, 2012; Kirk-Brown \& Van Dijk, 2016; Rusu, 2013). The study results indicate that OC is a mediator between EE and EP and that the relationship is stronger when employee job satisfaction is high. The present finding supports what scholars highlighted, that EE and JS have positive impacts on EP (Anitha, 2014; Ayub \& Islam, 2018; Chaudhry et al., 2017; Platis et al., 2015; Sendawula et al., 2018) and positive impact on OC (Eslami \& Gharakhani, 2012; Hanaysha, 2016a; Imam \& Shafique, 2014; Kirk-Brown \& Van Dijk, 2016; Nazir \& Islam, 2017; Rusu, 2013). The study results indicate that OC is a mediator between WE and EP and that the connection is stronger when employee job satisfaction is high. The present finding contradicts what scholars highlighted, that WE and JS have positive impacts on EP (Badrianto \& Ekhsan, 2020; Imran et al., 2012; Nguyen et al., 2015; Rorong, 2016) and positive impact on OC (Ahakwa, Yang, Tackie, Odai, et al., 2021; Eslami \& Gharakhani, 2012; Hanaysha, 2016a; Khuong \& Le Vu, 2014; Kirk-Brown \& Van Dijk, 2016; Rusu, 2013). The same findings were reported by Albalawi et al. (2019), who observed the variables inversely, where JS failed to moderate the link between perceived organizational support and OC. Our outcome adds to the literature's inconsistent findings; we attributed this to our approach and context; more research is needed to uncover why such association exists.

\section{Theoretical Implications}

In line with our expectations, we found that both EE and WE have a significant relationship with organizational commitment, which positively influences the performance of employees in every organization. Also, JS has a significant relationship with the performance of employees. This study will significantly contribute to the extant literature on the influence of EE, WE, and JS on OC and EP. Previous studies have equally researched into factors influencing OC and EP in different countries and firms and have recorded varying conclusions, for more reviews, see (Abdirahman, 2018; Cesário \& Chambel, 2017; Eliyana \& Ma'arif, 2019). However, this study will add to the literature on determinants of EP and OC in the banking sector of Ghana and other developing countries. Again, the result will add the scanty literature available and serve as a guide to other researchers about the use of sampling weights in PLS-SEM path modeling analysis.

\section{Managerial Implications}

There are several managerial implications of this study. First, our research findings advocate that managers should be familiar with the factors that influence EE and OC. This is mostly applicable in many sectors, including the service providers companies (e.g., banking) where employees are constantly facing job fatigue, which is likely to increases employee's decision to turnover. Importantly, it is prudent for managers to implement policies that will enhance OC and thus lead to EP. These policies should consider congruency between employee's JS, performance, WE, and organizational goals and aspirations. Moreover, managers should involve employees in decision-making processes to establish the factors that will increase EP and OC in their respective organizations. 
One significant managerial implication is seen in the finding that JS positively contributes to previous studies by impacting EP (Chaudhry, Jariko, Mushtaque, Mahesar, \& Ghani, 2017; Platis, Reklitis, \& Zimeras, 2015). This finding suggests that managers must consider the most effective factors that bring employees JS, which has a positive impact on the EP in an organization. Also, the study found that OC positively influences EP. Our result proposes that organizations may benefit more by promoting EP among workers dedicated to their organization.

In general terms, employees with higher levels of loyalty and fullness in an organization can mirror the positive behavior of their organizations and develop strong interests to continually work for their organizations. We suggest managers must promote employee satisfaction to win their loyalty and bring about organizational growth and development. However, employees who have less desire to be loyal to their organization may come as a result of managements' inability to provide good working conditions for employees and thus leads to poor organizational performance. It is therefore crucial for managers to maintain a good work atmosphere to encourage employees. Organizations and managers should then focus on developing the workers' workplace environment in numerous ways. This should entail valuing workers' contributions, communicating the company's progress and achievement to workers, thus instilling ownership in workers, providing them with a work-life balance, providing the requisite knowledge and tools for successful production, and providing a stable atmosphere. Management must have a place of work that guarantees the above. This will enable employees to give in their all and be committed to their organizations which serves as a driving force for organizational success and growth.

\section{Conclusion}

To a great extent, the exact estimation of people's beliefs, expectations, and values relies on how investigators choose respondents from a given population (J.-H. Cheah, Roldán, Ciavolino, Ting, \& Ramayah, 2020). PLSSEM users should be sufficiently conscious of sample collection factors, specifically when they intend their results to be relevant to the real world. Nevertheless, it is always unrealistic to obtain a sample that is reflective of a group of people. Also, the attainment of representativeness in sampling complicates problems, for instance, uneven selection probabilities, non-response, and non-coverage (Kalton \& Flores-Cervantes, 2003). Investigators using PLS-SEM should participate in an ex-post modification of the sampling weights to resolve this problem and implement the WPLS-SEM algorithm of Becker and Ismail (2016), which applies the sampling weights throughout the model estimation. Our analysis of the WPLS-SEM calculations and the normal PLSSEM evaluations makes little discrepancy in the assessment model outcomes compatible with Becker and Ismail's. However, our analysis indicates that major variations will exist if WPLS-SEM in the structural model assessment is not considered. The importance of the outcomes and the severity of the path coefficient, and the mediation effect assessment could be biased. Therefore, we propose that if investigators are interested in drawing population inferences, using the WPLS algorithm to build on less biased findings or assumptions, they should address the sampling discrepancies of their data collection. However, PLS-SEM better predicts the model in terms of $\mathrm{Q}^{2}$ and the PLSpredict (RMSE, MAE, $\mathrm{Q}^{2}$ predict), irrespective of both models (WPLS-SEM and PLS-SEM) having predictive relevance. All in all, our comparison reveals the weighting of the WPLS-SEM analysis of the sampling units and how they could achieve results that vary from a normal PLS-SEM analysis. This variability may have a significant effect on the empirical and managerial implications of the research and outcomes.

\section{Limitations and Recommendations}

The research did not involve people outside of Ghana. Future research may also be performed to address the limitations described by expanding the research to other settings and countries to achieve an extensive generalization of the analysis using WPLS-SEM and PLS-SEM. Future studies should also utilize the WPLS- 
SEM technique's effectiveness in accessing importance-performance map analysis (IPMA), multi-group analysis (MGA), and permutation analysis.

Abbreviations: EP (Employee Performance); OC (Organizational Commitment); JS (Job Satisfaction); WE (Work Environment); EE (Employee Engagement); PLS (Partial Least Squares); WPLS (Weighted Partial Least Squares); SEM (Structural Equation Modelling)

Funding: This research received no external funding.

Conflicts of Interest: The authors declare no conflict of interest.

\section{References}

Abdirahman, H. I. H. (2018). The relationship between job satisfaction, work-life balance and organizational commitment on employee performance.

Abdullah, A., \& Ramay, M. (2012). Antecedents of organizational commitment of banking sector employees in Pakistan. Serbian Journal of Management, 7(1), 89-102.

Abraham, S. (2012). Job satisfaction as an antecedent to employee engagement. sies Journal of Management, 8(2).

Ackah, D. (2014). The impact of motivation on employee performance in the manufacturing industry in Ghana. Global Journal of Management Studies and Researches, 1(5), 291-310.

Agbozo, G. K., Owusu, I. S., Hoedoafia, M. A., \& Atakorah, Y. B. (2017). The effect of work environment on job satisfaction: Evidence from the banking sector in Ghana. Journal of Human Resource Management, 5(1), 12-18.

Agyemang, C. B., \& Ofei, S. B. (2013). Employee work engagement and organizational commitment: A comparative study of private and public sector organizations in Ghana. European Journal of Business and Innovation Research, 1(4), 20-33.

Ahakwa, I., Yang, J., Agba Tackie, E., Afotey Odai, L., \& Dartey, S. (2021). The Effects of Job Autonomy, Organizational Learning, and Work Environment on Organizational Commitment of Public Sector Employees in the Ashanti Region of Ghana. International Journal of Scientific Research and Management, 9(1), 2099-2110. doi:10.18535/ijsrm/v9i1.em02

Ahakwa, I., Yang, J., Tackie, E. A., \& Bankole, K. (2021). Exploring the Impact of Traditional Communication Channels on Customer Purchase Decision: A Case Study of University Students in Ghana. SEISENSE Business Review, 1(1), 31-44.

Ahakwa, I., Yang, J., Tackie, E. A., Odai, L. A., \& Dartey, S. (2021). The Effects of Job Autonomy, Organizational Learning, and Work Environment on Organizational Commitment of Public Sector Employees in the Ashanti Region of Ghana.

Ahmad, N., Iqbal, N., Javed, K., \& Hamad, N. (2014). Impact of organizational commitment and employee performance on the employee satisfaction. International Journal of Learning, Teaching and Educational Research, 1(1), 84-92.

Ahmad, R., Islam, T., \& Saleem, S. (2019). How commitment and satisfaction explain leave intention in police force? Policing: an international journal.

Al-Ali, W., Ameen, A., Isaac, O., Khalifa, G. S., \& Shibami, A. H. (2019). The mediating effect of job happiness on the relationship between job satisfaction and employee performance and turnover intentions: A case study on the oil and gas industry in the United Arab Emirates. Journal of Business and Retail Management Research, 13(4).

Al-Omari, K., \& Okasheh, H. (2017). The influence of work environment on job performance: A case study of engineering company in Jordan. International Journal of Applied Engineering Research, 12(24), 1554415550. 
Albalawi, A. S., Naugton, S., Elayan, M. B., \& Sleimi, M. T. (2019). Perceived organizational support, alternative job opportunity, organizational commitment, job satisfaction and turnover intention: A moderated-mediated model. Organizacija, 52(4), 310-324.

Amoako-Asiedu, E., \& Obuobisa-Darko, T. (2017). Leadership, employee engagement and employee performance in the public sector of Ghana. Journal of Business and Management Sciences, 5(2), 27-34.

Ampomah, P. (2016). The Effect of Training and Development on Employee Performance in a Private Tertiary Institution in Ghana. Case Study: Pentecost University College (Puc)-Ghana). Asian Journal of Social Sciences and Management Studies, 3(1), 29-33.

Anindita, R., \& Seda, A. E. (2018). How employee engagement mediates the influence of individual factors toward organizational commitment. Problems and Perspectives in Management, 16(1), 276-283.

Anitha, J. (2014). Determinants of employee engagement and their impact on employee performance. International Journal of Productivity and Performance Management.

Anyakoha, C. (2019). Job analysis as a tool for improved organizational performance of SMEs in Lagos, Nigeria. Central European Journal of Labour Law and Personnel Management, 2(1), 7-16.

Ayub, N. B., \& Islam, M. K. (2018). The Effects of Employee Engagement on Employee Performance in the Hotel Industry in Kelantan. Global Business \& Management Research, 10(3).

Badran, M. A., \& Youssef-Morgan, C. M. (2015). Psychological capital and job satisfaction in Egypt. Journal of Managerial Psychology.

Badrianto, Y., \& Ekhsan, M. (2020). Effect of work environment and job satisfaction on employee performance in pt. Nesinak industries. Journal of Business Management and Accounting, 2(1), 322984.

Barrick, M. R., Stewart, G. L., \& Piotrowski, M. (2002). Personality and job performance: Test of the mediating effects of motivation among sales representatives. Journal of applied psychology, 87(1), 43.

Becker, J.-M., \& Ismail, I. R. (2016). Accounting for sampling weights in PLS path modeling: Simulations and empirical examples. European Management Journal, 34(6), 606-617.

Berberoglu, A. (2015). Organizational commitment and perceived organizational performance among health care professionals: Empirical evidence from a private Hospital in Northern Cyprus. Journal of Economics and Behavioral Studies, 7(1 (J)), 64-71.

Boadu, F., Dwomo-Fokuo, E., Boakye, J. K., \& Kwaning, C. O. (2014). Training and development: A tool for employee performance in the district assemblies in Ghana. International Journal of Education and Research, 2(5), 130-146.

Cesário, F., \& Chambel, M. J. (2017). Linking organizational commitment and work engagement to employee performance. Knowledge and Process Management, 24(2), 152-158.

Chandrasekar, K. (2011). Workplace environment and its impact on organisational performance in public sector organisations. International journal of enterprise computing and business systems, 1(1), 1-19.

Chaudhary, S., Bidlan, J., \& Darolia, C. (2015). A study of relationship of psychological capital with job satisfaction and turnover intention of LIC employees. Indian Journal of Health and Wellbeing, 6(7), 692.

Chaudhry, N. I., Jariko, M. A., Mushtaque, T., Mahesar, H. A., \& Ghani, Z. (2017). Impact of working environment and training \& development on organization performance through mediating role of employee engagement and job satisfaction. European Journal of Training and Development Studies, 4(2), 3348.

Cheah, C. S., Chong, V. S. W., Yeo, S. F., \& Pee, K. W. (2016). An empirical study on factors affecting organizational commitment among generation X. Procedia-Social and Behavioral Sciences, 219, 167-174.

Cheah, J.-H., Roldán, J. L., Ciavolino, E., Ting, H., \& Ramayah, T. (2020). Sampling weight adjustments in partial least squares structural equation modeling: guidelines and illustrations. Total Quality Management \& Business Excellence, 1-20.

Chin, W. W., Peterson, R. A., \& Brown, S. P. (2008). Structural equation modeling in marketing: Some practical reminders. Journal of Marketing theory and Practice, 16(4), 287-298. 
Cohen, S. (1988). Perceived stress in a probability sample of the United States.

Conway, J. M., \& Lance, C. E. (2010). What reviewers should expect from authors regarding common method bias in organizational research. Journal of Business and Psychology, 25(3), 325-334.

Cropanzano, R., Rupp, D. E., \& Byrne, Z. S. (2003). The relationship of emotional exhaustion to work attitudes, job performance, and organizational citizenship behaviors. Journal of Applied psychology, 88(1), 160.

Dahie, A. M., Takow, M. A., Nur, A. H., \& Osman, M. M. (2016). Organizational culture and employee performance at telecommunication firms in Mogadishu-Somalia. International Journal in Commerce, IT \& Social Sciences, 3(1), 30-41.

Danish, R. Q., Ramzan, S., \& Ahmad, F. (2013). Effect of perceived organizational support and work environment on organizational commitment; mediating role of self-monitoring. Advances in Economics and Business, 1(4), 312-317.

Darma, P. S., \& Supriyanto, A. S. (2017). The effect of compensation on satisfaction and employee performance. Management and Economics Journal (MEC-J), 1(1).

Dhir, S., \& Shukla, A. (2018). The influence of personal and organisational characteristics on employee engagement and performance. International Journal of Management Concepts and Philosophy, 11(2), 117-131.

Dixit, V., \& Bhati, M. (2012). A study about employee commitment and its impact on sustained productivity in Indian auto-component industry. European journal of business and social sciences, 1(6), 34-51.

Dormann, C. F., Elith, J., Bacher, S., Buchmann, C., Carl, G., Carré, G., . . Leitao, P. J. (2013). Collinearity: a review of methods to deal with it and a simulation study evaluating their performance. Ecography, $36(1), 27-46$.

Eliyana, A., \& Ma'arif, S. (2019). Job satisfaction and organizational commitment effect in the transformational leadership towards employee performance. European Research on Management and Business Economics, 25(3), 144-150.

Eslami, J., \& Gharakhani, D. (2012). Organizational commitment and job satisfaction. ARPN journal of science and technology, 2(2), 85-91.

Fornell, C., \& Bookstein, F. L. (1982). Two structural equation models: LISREL and PLS applied to consumer exit-voice theory. Journal of Marketing research, 19(4), 440-452.

Fornell, C., \& Larcker, D. F. (1981). Evaluating structural equation models with unobservable variables and measurement error. Journal of marketing research, 18(1), 39-50.

Fu, W., \& Deshpande, S. P. (2014). The impact of caring climate, job satisfaction, and organizational commitment on job performance of employees in a China's insurance company. Journal of business ethics, 124(2), 339-349.

Giffords, E. D. (2009). An examination of organizational commitment and professional commitment and the relationship to work environment, demographic and organizational factors. Journal of Social Work, 9(4), 386-404.

Grewal, R., Cote, J. A., \& Baumgartner, H. (2004). Multicollinearity and measurement error in structural equation models: Implications for theory testing. Marketing science, 23(4), 519-529.

Haggins, R. (2011). A correlational study of work environment factors and organizational commitment in southern California staff nurses. University of Phoenix.

Hair, J. F., Astrachan, C. B., Moisescu, O. I., Radomir, L., Sarstedt, M., Vaithilingam, S., \& Ringle, C. M. (2020). Executing and interpreting applications of PLS-SEM: Updates for family business researchers. Journal of Family Business Strategy, 100392.

Hair Jr, J. F., Hult, G. T. M., Ringle, C., \& Sarstedt, M. (2016). A primer on partial least squares structural equation modeling (PLS-SEM): Sage publications.

Hanaysha, J. (2016a). Testing the effects of employee engagement, work environment, and organizational learning on organizational commitment. Procedia-Social and Behavioral Sciences, 229, 289-297. 
Hanaysha, J. (2016b). Testing the effects of employee engagement, work environment, and organizational learning on organizational commitment. Procedia-Social and Behavioral Sciences, 229(8), 289-297.

Hayat, A., Azeem, M., Nawaz, R., Humayon, D. A. A., \& Ahmed, D. M. (2019). Mediating Effect of Human Capital on Organizational Culture, Teamwork, Organizational Development and Organizational Commitment. Journal of Social Sciences and Humanity Studies, 5(3), 1-9.

Hendri, N. (2019). The impact of organizational commitment on job performance.

Henseler, J., Ringle, C. M., \& Sarstedt, M. (2015). A new criterion for assessing discriminant validity in variance-based structural equation modeling. Journal of the academy of marketing science, 43(1), 115-135.

Hidayah, T., \& Tobing, D. S. K. (2018). The influence of job satisfaction, motivation, and organizational commitment to employee performance.

Igbaria, M., \& Greenhaus, J. H. (1992). Determinants of MIS employees' turnover intentions: a structural equation model. Communications of the ACM, 35(2), 34-49.

Imam, A., \& Shafique, M. (2014). Impact of employee engagement in retaining employees through mediating effect of job satisfaction and organizational commitment and moderating effect of job stress: A Corporate banking sector study of Pakistan. Journal of Applied Environmental and Biological Sciences, 4(12), 1-15.

Imran, R., Fatima, A., Zaheer, A., Yousaf, I., \& Batool, I. (2012). How to boost employee performance: investigating the influence of transformational leadership and work environment in a Pakistani perspective. Middle-East Journal of Scientific Research, 11(10), 1455-1462.

Inuwa, M. (2016). Job satisfaction and employee performance: An empirical approach. The Millennium University Journal, 1(1), 90-103.

Jamal, M. (2011). Job stress, job performance and organizational commitment in a multinational company: An empirical study in two countries. International Journal of Business and Social Science, 2(20).

Jiony, M. M., Tanakinjal, G. H., Gom, D., \& Siganul, R. S. (2015). Understanding the effect of organizational culture and employee engagement on organizational performance using organizational communication as mediator: a conceptual framework. American Journal of economics, 5(2), 128-134.

Joe-Akunne, C., \& Ezeh, L. N. (2019). Organizational commitment among private sector workers in anambra state, nigeria. Practicum Psychologia, 9(1).

Judge, T. A., \& Locke, E. A. (1993). Effect of dysfunctional thought processes on subjective well-being and job satisfaction. Journal of Applied psychology, 78(3), 475.

Kalton, G., \& Flores-Cervantes, I. (2003). Weighting methods. Journal of official statistics, $19(2), 81$.

Kang, M., \& Sung, M. (2017). How symmetrical employee communication leads to employee engagement and positive employee communication behaviors: The mediation of employee-organization relationships. Journal of Communication Management.

Karacsony, P. (2019). Examining the Relationship Between Workplace Stress and Organizational Commitment. Paper presented at the Proceedings of the 2019 International Conference on Management Science and Industrial Engineering.

Karunarathne, E., \& Wickramasekara, A. (2020). Middle level managers'organizational commitment on their job performance in agricultural input distributing companies in sri lanka. International Journal of Information, Business and Management, 12(4), 28-38.

Khalid, A., \& Khalid, S. (2015). Relationship between organizational commitments, employee engagement and career satisfaction a case of university of Gujrat, Pakistan. Journal of South Asian Studies, 3(3), 323330.

Khuong, M. N., \& Le Vu, P. (2014). Measuring the effects of drivers organizational commitment through the mediation of job satisfaction: A Study in Ho Chi Minh City, Vietnam. International Journal of Current Research and Academic Review, 2(2), 1-16.

Kim, J. H. (2019). Multicollinearity and misleading statistical results. Korean journal of anesthesiology, 72(6), 558. 
Kim, W., Khan, G. F., Wood, J., \& Mahmood, M. T. (2016). Employee engagement for sustainable organizations: Keyword analysis using social network analysis and burst detection approach. Sustainability, 8(7), 631.

Kirk-Brown, A., \& Van Dijk, P. (2016). An examination of the role of psychological safety in the relationship between job resources, affective commitment and turnover intentions of Australian employees with chronic illness. The International Journal of Human Resource Management, 27(14), 1626-1641.

Kline, R. B. (2011). Convergence of structural equation modeling and multilevel modeling: na.

Kock, N. (2015). Common method bias in PLS-SEM: A full collinearity assessment approach. International Journal of e-Collaboration (ijec), 11(4), 1-10.

Kruse, K. (2012). What is employee engagement. http:// wmw. forbes. com/ sites/kevinkruse/2012/06/22/ employeeengagementwhat-and-why/, Article quoted on June, 22, 2012.

Kuruppuge, R. H., \& Gregar, A. (2017). Family involvement, employee engagement and employee performance in enterprising family firms. Acta Universitatis Agriculturae et Silviculturae Mendelianae Brunensis.

Le, B. P., \& Tran, Q. T. (2020). Leadership practice for building trust of followers: Decisive factors of organizational performance. SEISENSE Journal of Management, 3(2), 45-57.

Lee, T. W., Ashford, S. J., Walsh, J. P., \& Mowday, R. T. (1992). Commitment propensity, organizational commitment, and voluntary turnover: A longitudinal study of organizational entry processes. Journal of management, 18(1), 15-32.

Liu, Y., Aungsuroch, Y., \& Yunibhand, J. (2016). Job satisfaction in nursing: a concept analysis study. International nursing review, 63(1), 84-91.

Lockwood, N. R. (2007). Leveraging employee engagement for competitive advantage. Society for Human Resource Management Research Quarterly, 1(1), 1-12.

Lutwama, G. W. (2011). The performance of health workers in decentralised services in Uganda. University of South Africa Dissertation.

McGuire, D., \& McLaren, L. (2009). The impact of physical environment on employee commitment in call centres. Team Performance Management: An International Journal.

Men, L. R., O’Neil, J., \& Ewing, M. (2020). Examining the effects of internal social media usage on employee engagement. Public Relations Review, 46(2), 101880.

Monica, R., \& Krishnaveni, R. (2018). Enablers of employee engagement and its subsequent impact on job satisfaction. International Journal of Human Resources Development and Management, 18(1-2), 5-31.

Motowidlo, S. J., Lievens, F., \& Ghosh, K. (2018). Prosocial implicit trait policies underlie performance on different situational judgment tests with interpersonal content. Human Performance, 31(4), 238-254.

Muntazeri, S., \& Indrayanto, A. (2018). The impact of education, training and work experience on job satisfaction and job performance. Jurnal Akuntansi, Manajemen Dan Ekonomi, 20(2), 50-69.

NATH, G. K., \& Agrawal, R. (2015). Job satisfaction and organizational commitment: Is it important for employee performance.

Nazir, O., \& Islam, J. U. (2017). Enhancing organizational commitment and employee performance through employee engagement. South Asian Journal of Business Studies.

Nematchoua, M. K., Ricciardi, P., Orosa, J. A., Asadi, S., \& Choudhary, R. (2019). Influence of indoor environmental quality on the self-estimated performance of office workers in the tropical wet and hot climate of Cameroon. Journal of Building Engineering, 21, 141-148.

Nguyen, P. D., Dang, C. X., \& Nguyen, L. D. (2015). Would better earning, work environment, and promotion opportunities increase employee performance? An investigation in state and other sectors in Vietnam. Public Organization Review, 15(4), 565-579. 
Nwachukwu, P., Ezeh, J. I., Ogochukwu, O. E., Nkechinyere, O., \& Dumle, N. (2019). Work Environment and Employee's Commitment in Three Selected Institutions in Rivers State. International Journal of Engineering and Management Research, 9.

Obicci, P. A. (2015). Effects of ethical leadership on employee performance in Uganda. Net journal of business management, 3(1), 1-12.

Obuobisa-Darko, T. (2019). Leaders' Behaviour as a Determinant of Employee Performance in Ghana: The Mediating Role of Employee Engagement. Public Organization Review, 1-15.

Odom, R. Y., Boxx, W. R., \& Dunn, M. G. (1990). Organizational cultures, commitment, satisfaction, and cohesion. Public Productivity \&amp; Management Review, 157-169.

Otoo, F. (2016). Effect of communication on employee performance at Ghana Revenue Authority, Kumasi.

Paramita, E., Lumbanraja, P., \& Absah, Y. (2020). The Influence of Organizational Culture and Organizational Commitment on Employee Performance and Job Satisfaction as a Moderating Variable at PT. Bank Mandiri (Persero), Tbk. Tbk. International Journal of Research and Review, 7(3), 273286.

Pitaloka, E., \& Sofia, I. P. (2014). The affect of work environment, job satisfaction, organization commitment on OCB of internal auditors. International Journal of Business, Economics and Law, 5(2), 10-18.

Platis, C., Reklitis, P., \& Zimeras, S. (2015). Relation between job satisfaction and job performance in healthcare services. Procedia-Social and Behavioral Sciences, 175, 480-487.

Pohler, D., \& Schmidt, J. A. (2016). Does pay-for-performance strain the employment relationship? The effect of manager bonus eligibility on nonmanagement employee turnover. Personnel Psychology, 69(2), 395-429.

Porter, L. W., Steers, R. M., Mowday, R. T., \& Boulian, P. V. (1974). Organizational commitment, job satisfaction, and turnover among psychiatric technicians. Journal of Applied psychology, 59(5), 603.

Putri, E. M., Ekowati, V. M., Supriyanto, A. S., \& Mukaffi, Z. (2019). The Effect of Work Environment on Employee Performance Through Work Discipline. International Journal of Research-

GRANTHAALAYAH, 7(4), 132-140.

Putri, W. H., \& Setianan, A. R. (2019). Job enrichment, organizational commitment, and intention to quit: the mediating role of employee engagement. Problems and Perspectives in Management, 17(2), 518.

Qureshi, M. A., \& Hamid, K. (2017). Impact of supervisor support on job satisfaction: A moderating role of fairness perception. International Journal of Academic Research in Business and Social Sciences, 7(3), 235-242.

Ramli, A. H. (2019). Organizational commitment and employee performance at distributor companies. Business and Entrepreneurial Review, 17(2), 121-134.

Rayton, B. A. (2006). Examining the interconnection of job satisfaction and organizational commitment: An application of the bivariate probit model. The International Journal of Human Resource Management, 17(1), 139-154.

Raziq, A., \& Maulabakhsh, R. (2015). Impact of working environment on job satisfaction. Procedia Economics and Finance, 23, 717-725.

Rorong, S. V. (2016). The impact of physical work environment toward employee performance at PT. Bank Negara Indonesia Manado Regional Office. Jurnal EMBA: Jurnal Riset Ekonomi, Manajemen, Bisnis dan Akuntansi, 4(1).

Rothmann, S. (2017). Employee engagement. The Wiley Blackwell handbook of the psychology of positivity and strengths-based approaches at work, 317-341.

Rusu, R. (2013). Organizational commitment and job satisfaction. Buletin Stïntific, 18(1).

Saks, A. M. (2019). Antecedents and consequences of employee engagement revisited. Journal of Organizational Effectiveness: People and Performance.

Schaufeli, W. B. (2013). What is engagement. Employee engagement in theory and practice, 15, 321. 
Schaufeli, W. B., \& Bakker, A. B. (2004). Job demands, job resources, and their relationship with burnout and engagement: A multi-sample study. Journal of Organizational Behavior: The International Journal of Industrial, Occupational and Organizational Psychology and Behavior, 25(3), 293-315.

Sendawula, K., Kimuli, S. N., Bananuka, J., \& Muganga, G. N. (2018). Training, employee engagement and employee performance: Evidence from Uganda's health sector. Cogent Business \& Management, 5(1), 1470891.

Shah, N. H., \& Jumani, N. B. (2015). Relationship of job satisfaction and turnover intention of private secondary school teachers. Mediterranean Journal of Social Sciences, 6(4), 313-313.

Shmueli, G., Sarstedt, M., Hair, J. F., Cheah, J.-H., Ting, H., Vaithilingam, S., \& Ringle, C. M. (2019). Predictive model assessment in PLS-SEM: guidelines for using PLSpredict. European Journal of Marketing.

Shuck, B., Reio Jr, T. G., \& Rocco, T. S. (2011). Employee engagement: An examination of antecedent and outcome variables. Human resource development international, 14(4), 427-445.

Singh, V. (2019). The Impact of Job Engagement and Organizational Commitment on Organizational Performance: Evidence from India Management Techniques for Employee Engagement in Contemporary Organizations (pp. 218-235): IGI Global.

Somers, M. J. (1995). Organizational commitment, turnover and absenteeism: An examination of direct and interaction effects. Journal of organizational Behavior, 16(1), 49-58.

Stajkovic, A. D., \& Luthans, F. (1998). Self-efficacy and work-related performance: A meta-analysis. Psychological bulletin, 124(2), 240.

Storm, K., \& Rothmann, S. (2003). A psychometric analysis of the Utrecht Work Engagement Scale in the South African police service. SA Journal of Industrial Psychology, 29(4), 62-70.

Sugianingrat, I. A. P. W., Widyawati, S. R., da Costa, C. A. d. J., Ximenes, M., Piedade, S. D. R., \& Sarmawa, W. G. (2019). The employee engagement and OCB as mediating on employee performance. International Journal of Productivity and Performance Management.

Suliman, A. M., \& Iles, P. A. (2000). The multi-dimensional nature of organisational commitment in a nonwestern context. Journal of management development.

Susanty, A., \& Miradipta, R. (2013). Employee's job performance: The effect of attitude toward works, organizational commitment, and job satisfaction. Jurnal Teknik Industri, 15(1), 13-24.

Syauta, J. H., Troena, E. A., \& Margono Setiawan, S. (2012). The influence of organizational culture, organizational commitment to job satisfaction and employee performance (study at municipal waterworks of Jayapura, Papua Indonesia). International Journal of Business and Management Invention, 1(1), 69-76.

Tackie, E. A., Chen, H., Ahakwa, I., Atingabilli, S., Ansah, K. A., \& Baku, R. (2020). Integration of Economic, Educational and Socio-Cultural Capabilities for Rural Poverty Alleviation in Northern Ghana. Integration, 5(1).

Thakur, P. (2014). A research paper on the effect of employee engagement on job satisfaction in IT sector. Journal of Business Management \& Social Sciences Research, 3(5), 31-39.

Truss, C., Shantz, A., Soane, E., Alfes, K., \& Delbridge, R. (2013). Employee engagement, organisational performance and individual well-being: exploring the evidence, developing the theory: Taylor \& Francis.

Vanaki, Z., \& Vagharseyyedin, S. A. (2009). Organizational commitment, work environment conditions, and life satisfaction among Iranian nurses. Nursing \& health sciences, 11(4), 404-409.

Vorina, A., Simonič, M., \& Vlasova, M. (2017). An analysis of the relationship between job satisfaction and employee engagement. Economic Themes, 55(2), 243-262.

Vrinda, N., \& Jacob, N. A. (2015). The impact of job satisfaction on job performance. International Journal in Commerce, IT \& Social Sciences, 2(2), 27-37. 
Wamba, S. F., Gunasekaran, A., Akter, S., Ren, S. J.-f., Dubey, R., \& Childe, S. J. (2017). Big data analytics and firm performance: Effects of dynamic capabilities. Journal of Business Research, 70, 356-365.

Weiss, D. J., Dawis, R. V., \& England, G. W. (1967). Manual for the Minnesota satisfaction questionnaire. Minnesota studies in vocational rehabilitation.

Yousef, D. A. (2017). Organizational commitment, job satisfaction and attitudes toward organizational change: A study in the local government. International Journal of Public Administration, 40(1), 77-88.

Yuniarti, W. N., \& Prasetyaningtyas, S. W. (2020). The influence of organizational commitment to employee performance with employee engagement and organizational culture as a mediator In private banking company. Psychology and Education Journal, 57(9), 401-410.

Zainudin, M. I., Rashid, M. S. A., Murugeesan, Y., Che Zainal, C. N. A. S., \& Malek, S. N. A. (2019). Islamic Working Environment, Organizational Commitment and Employee's Job Satisfaction and Performance in Malaysia Service Industry: A Conceptual Paper. Global Business \& Management Research, 11(1). 